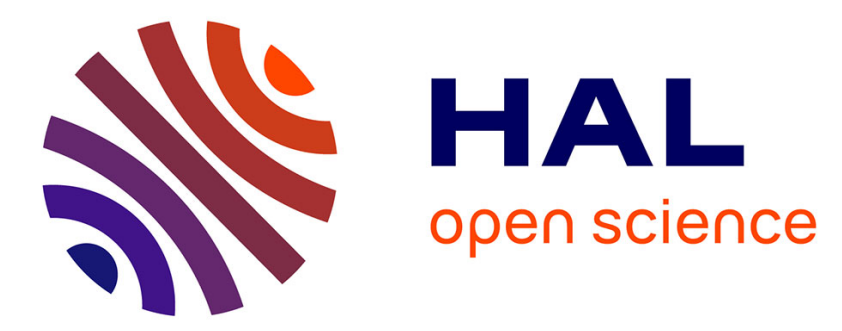

\title{
The Counterparty Risk Exposure of ETF Investors
}

Christophe Hurlin, Gregoire Iseli, Christophe Pérignon, Stanley Yeung

\section{To cite this version:}

Christophe Hurlin, Gregoire Iseli, Christophe Pérignon, Stanley Yeung. The Counterparty Risk Exposure of ETF Investors. 2014. halshs-01023807v3

\section{HAL Id: halshs-01023807 https://shs.hal.science/halshs-01023807v3}

Preprint submitted on 14 Dec 2015

HAL is a multi-disciplinary open access archive for the deposit and dissemination of scientific research documents, whether they are published or not. The documents may come from teaching and research institutions in France or abroad, or from public or private research centers.
L'archive ouverte pluridisciplinaire HAL, est destinée au dépôt et à la diffusion de documents scientifiques de niveau recherche, publiés ou non, émanant des établissements d'enseignement et de recherche français ou étrangers, des laboratoires publics ou privés. 


\title{
The Counterparty Risk Exposure of ETF Investors
}

\author{
Christophe Hurlin, Grégoire Iseli, Christophe Pérignon, and Stanley Yeung *
}

November 25, 2015

\begin{abstract}
As most Exchange-Traded Funds (ETFs) engage in securities lending or are based on total return swaps, they expose their investors to counterparty risk. In this paper, we estimate empirically such risk exposures for a sample of physical and swap-based funds. We find that counterparty risk exposure is higher for swap-based ETFs, but that investors are compensated for bearing this risk. Using a difference-in-differences specification, we uncover that ETF flows respond significantly to changes in counterparty risk. Finally, we show that switching to an optimal collateral portfolio leads to substantial reduction in counterparty risk exposure.
\end{abstract}

Keywords: Asset management, collateral, derivatives, regulatory arbitrage, systemic risk. JEL classification: G20, G23

${ }^{*}$ Hurlin is at the University of Orléans, France; Iseli, Pérignon and Yeung are at HEC Paris, France. Email and phone of corresponding author: perignon@hec.fr, +331396794 11. We are grateful to Tony Berrada, Hortense Bioy, Caitlin Dannhauser, Thierry Foucault, Laurent Frésard, Francesco Franzoni, Denis Gromb, Johan Hombert, Hugues Langlois, Arnaud Llinas, Denis Panel, Manooj Mistry, Jeffrey Pontiff, Sébastien Ringuedé, Richard Roll, Thierry Roncalli, Ioanid Rosu, Jean-David Sigaux, Guillaume Vuillemey, to seminar participants at the Autorité de Contrôle Prudentiel et de Résolution (ACPR), BNP-Paribas, the European Securities and Markets Authority (ESMA), Institut Louis Bachelier, Lyxor, University of Geneva, University of Neuchatel, and University of Orléans, and to participants at the 2015 European Financial Management Association Meeting, 2015 French Finance Association Meeting, and 2015 Annual Workshop of the Dauphine-Amundi Chair in Asset Management for their comments. We are grateful to the Chair ACPR/Risk Foundation: Regulation and Systemic Risk and to the Amundi-Dauphine Chair in Asset Management for supporting our research. 
"If you buy a Lyxor product, you're an unsecured creditor of SocGen."

Laurence D. Fink, CEO of BlackRock (the leading physical ETF issuer), Bloomberg (2011).

\section{Introduction}

With their low fees and ability to provide exposure to a variety of asset classes, exchangetraded funds (ETFs) have become popular investment vehicles among individual and institutional investors alike. The global ETF industry reached a total of $\$ 3$ trillion in assets under management (AUM) in 2015-Q3 and experienced an average growth of $28 \%$ per year for the past fifteen years (BlackRock, 2015).

ETFs come in two types. In a physical ETF, investors' money is directly invested in the index constituents in order to replicate the index return. Differently in a synthetic ETF, the fund issuer enters into a total return swap with a financial institution which promises to deliver the performance of the index to the fund (Ramaswamy, 2011). An industry survey by Vanguard (2013) indicates that $17 \%$ of the ETFs in the US are synthetic compared to $69 \%$ in Europe. ${ }^{1}$ Furthermore, most leveraged and inverse ETFs traded in the world are based on synthetic replications (Tang and $\mathrm{Xu}, 2013$ ).

In this paper, we empirically estimate the counterparty risk exposure of ETF investors. Indeed, physical ETF issuers generate extra revenues by engaging in securities lending (Blocher and Whaley, 2015). Hence, there is a possibility that the securities on loan will not be returned in due time. Furthermore, for synthetic ETFs, there is a risk that the total

\footnotetext{
${ }^{1}$ Synthetic ETFs are less common in the US because (1) swaps between affiliated parties are not permitted under the Investment Company Act of 1940 and (2) swap income faces a higher tax rate than capital gains incurred by transacting in the underlying securities. Other examples of investment vehicles built on derivatives include the retail structured products studied in Célérier and Vallée (2015). For papers on derivative usage by mutual funds and hedge funds, see Koski and Pontiff (1999) and Chen (2011).
} 
return swap counterparty will fail to deliver the index return. In order to mitigate counterparty risk, both securities lending positions and swaps must be collateralized. Recently, the Financial Stability Board (2011) and the International Monetary Fund (2011) warned about potential financial stability issues that may arise from synthetic ETFs. The latter were accused of being poorly collateralized and allowing banks to engage in regulatory arbitrage by using risky assets as collateral.

We define counterparty risk of ETFs as the risk that the value of the collateral falls below the Net Asset Value (NAV) of the fund when the fund counterparty is in default. To quantify this risk empirically, we analyze the composition of the collateral portfolios of a sample of physical and synthetic ETFs managed by two leading ETF issuers, BlackRock and $\mathrm{db} \mathrm{X}$-trackers. For each fund, we know the exact composition of the collateral portfolio at the end of each week. This is to the best of our knowledge the first time that such a dataset is used in an academic study. The high granularity of our data allows us to study empirically the counterparty risk of ETFs for various asset classes, regional exposures, and types of replication.

Our analysis of the collateral portfolios of synthetic funds reveals several important features of collateral management. First, collateral portfolios are well diversified and their value often exceeds the NAV of the fund (the average collateralization is 108.4\%). Second, there is a good fit between the asset exposure of the fund (e.g. equity or fixed income) and the collateral used to secure the swap. This feature is important given the fact that in the case of a default of the swap counterparty, the asset manager would need to sell collateral to meet redemptions from investors. Third, ETF collateral is of high quality (e.g. equities from large 
firms and highly-rated bonds).

We quantify the counterparty risk exposure of investors using the expected magnitude of the collateral shortfall. This measure is computed conditionally on the default of the fund counterparty. When contrasting the level of counterparty risk exposure of investors in synthetic and physical ETFs, we find that counterparty risk exposure is higher for synthetic funds but that investors are compensated for bearing this risk through lower tracking errors and similar or lower fees. We also show that ETF investors do care about counterparty risk. Indeed, using a difference-in-differences approach, we find that there are more outflows from synthetic ETFs after an increase in counterparty risk.

In a final step, we theoretically show how to design an optimal collateral portfolio that aims to minimize the counterparty risk exposure of ETF investors. The composition of the optimal collateral portfolio is obtained by maximizing the investors' expected utility, defined as a decreasing function of the collateral shortfall. Using our sample of ETFs, we find that, on average, switching from an actual collateral portfolio to an optimal collateral portfolio would lead to a $23 \%$ reduction in counterparty risk exposure.

Our paper contributes to the growing literature on the potential financial stability issues arising from ETFs. ${ }^{2}$ Malamud (2015) derives a dynamic general equilibrium model of ETFs that accounts for the share creation/redemption mechanism conducted by "Authorized Participants" in the primary market. Contrary to the prevailing view among regulators, he shows that ETF trading does not always increase the volatility of the underlying asset. Fur-

\footnotetext{
${ }^{2}$ For additional evidence on the link between asset management and financial stability, see Coval and Stafford (2007), Mitchell, Pedersen and Pulvino (2007), Boyson, Stahel and Stulz (2010), Chen, Goldstein and Jiang (2010), Jotikasthira, Lundblad and Ramadorai (2012), Kacperczyk and Schnabl (2013), and Schmidt, Timmermann and Wermers (2014).
} 
thermore, in this model, introducing new ETFs can reduce co-movement in the returns and improve the liquidity of the underlying securities. There are a large number of empirical papers focusing on one particular effect of ETF trading. Ben-David, Franzoni and Moussawi (2014) empirically show that ETF ownership increases stock volatility. Their identification strategy is based on the mechanical variation in ETF ownership due to stocks switching from the Russell 1000 index to the Russel 2000 index; hence attracting more holdings from index funds. Da and Shive (2013) find a strong relation between measures of ETF activity and return comovement among stocks. Dannhauser (2014) shows that corporate bond ETFs have an insignificant or negative impact on the liquidity of constituent bonds (see Hamm, 2014, for evidence on equity funds).

Focusing on the real effects of ETF rebalancing activities, Bessembinder et al. (2015) report no evidence of predatory trading around the time of the Crude Oil ETFs rolls of crude oil futures (for a broader analysis of the effects of predictable institutional orders, see Bessembinder, 2015). Focusing on leveraged and inverse funds, Bai, Bond and Hatch (2012) find that late-day leveraged ETF rebalancing activity significantly moves the price of constituent stocks (see also Shum et al., 2014, Tuzun, 2014, Ivanov and Lenkey, 2014).

Unlike previous academic studies, we do not focus on the interplay between the ETFs and the assets they track. Instead, our study considers a source of risk that has been neglected so far in the academic literature: the counterparty risk of ETFs. We make several contributions to the existing literature. To the best of our knowledge, our study is the first attempt to assess empirically the quality of the collateral for a large and representative sample of ETFs. Our second contribution is to empirically compare the counterparty risk exposures of ETF 
investors and identify the types of funds that expose the most their investors to this risk. We also analyze how investors react to changes in the level of counterparty risk they are exposed to. Finally, we contrast actual and optimal collateral portfolios, which lead by design to the lowest possible level of counterparty risk. We believe that this is the first attempt to derive optimal allocation rules for collateral portfolios, which is a topic of growing importance given the emphasis put on collateral by the recent financial regulatory reform (Dodd Franck in the US and EMIR in Europe).

The rest of our study is structured as follows. In Section 2, we explain why and how ETFs can expose their investors to counterparty risk. Section 3 presents our collateral data. In Section 4, we empirically estimate counterparty risk exposures for our sample funds and test whether investors care about this source of risk. In Section 5, we show how to build an optimal collateral portfolio that aims to minimize investors' counterparty risk exposure. We conclude our study in Section 6 .

\section{Sources of Counterparty Risk in ETFs}

\subsection{Physical Model}

Physical ETFs track their target index by holding all, or a representative sample, of the underlying securities that make up the index (see Figure 1, Panel A). For example, if you invest in an S\&P $500 \mathrm{ETF}$, you own each of the 500 securities represented in the S\&P 500 Index, or some subset of them. Almost all ETF issuers have the provision in their prospectus for loaning out their stock temporarily for revenue. Over the period 2009-2013, Blocher and Whaley (2015) estimate that the revenues generated by ETFs through securities lending are comparable in size with management fees. 
Securities lending exposes ETF investors to counterparty risk. In order to mitigate this risk, short sellers have to post collateral with the ETF issuer. On a given point in time, a collateral shortfall occurs if the value of the collateral is less than the current NAV of the fund. Such a situation can be problematic if the short sellers cannot return to the fund the borrowed securities in due time, i.e., if some of them default. In that case, the fund will not be able to meet redemption requests from all investors.

\section{$2.2 \quad$ Swap-based Model}

First introduced in the early 2000's, synthetic ETFs are an interesting variant of physical ETFs. The most commonly used structure for synthetic replications is the unfunded swap model. In this model, the ETF issuer enters into a total return swap with a counterparty, which can either be an affiliated bank from the same banking group or another bank (see Figure 1, Panel B). The swap counterparty commits to deliver the return of the reference index and sells a substitute basket of securities to the ETF issuer. The second leg of the swap consists of the performance of the basket of securities paid by the issuer to the swap counterparty. An important feature of this model is that the ETF issuer becomes the legal owner of the assets and enjoys direct access to them. This means that if the swap counterparty defaults, the ETF issuer can immediately liquidate the assets. ${ }^{3}$

One may wonder why synthetic replication was invented. First, it is more convenient and cheaper for the ETF issuer to outsource the index replication rather than dealing itself with

\footnotetext{
${ }^{3}$ An alternative, though less frequent, structure is the funded swap model. Under this swap agreement, the ETF issuer transfers investors' cash to a swap counterparty in exchange for the index performance plus the principal at a future date. The swap counterparty pledges collateral assets in a segregated account with a third party custodian. The posted collateral basket is made of securities which come from the counterparty's inventory and meet certain conditions in terms of asset type, liquidity, and diversification. In practice, appropriate haircuts apply to the assets posted as collateral to account for the risk of value fluctuations and for imperfect correlation between the index and the collateral value.
} 
dividend flows, corporate events, changes in index composition, or storage for commodities. ${ }^{4}$ Second, swap-based replications limit investors' exposure to tracking error risk (see Section 4.3 below). Third, synthetic replication greatly simplifies the tracking of illiquid assets as well as the issuance of inverse funds. Fourth, these swaps constitute a major source of funding for financial institutions and lead to synergies and cost saving with their investment banks which maintain large inventories of equities and bonds. Finally, they may also allow the banks that act as swap counterparties to reduce their regulatory capital by posting high risk-weight securities as collateral.

The counterparty exposure of the issuer, or swap value, is measured as the difference between the NAV and the value of the substitute basket (per share) used as collateral. The swap is marked to market at the end of each day and reset whenever the counterparty exposure exceeds a given threshold expressed as a percentage of the NAV. It is worth noting that synthetic-ETF investors are particularly exposed to counterparty risk in the case of an inverse ETF. In this case, the bank that acts as the swap counterparty must deliver a return that increases with the severity of a stock market crash, i.e., when the default probability of the bank is particularly high and when the value of the collateral is particularly low. This is clearly a case of wrong-way risk.

\section{$3 \quad$ Data and Descriptive Statistics}

\section{$3.1 \quad$ Types of Funds}

Our empirical analysis is based on a sample of 218 ETFs with $\$ 115.4$ billion combined AUM. An attractive feature of our sample is that it includes both synthetic and physical

\footnotetext{
${ }^{4}$ An industry survey by Morningstar (2012) indicates that swap fees are extremely low and can even be zero if the swap is entered with an investment bank from the same banking group.
} 
ETFs. ${ }^{5}$ We see in Table 1 that the 164 synthetic ETFs have combined AUM of $\$ 37.9$ billion, which is approximately $30 \%$ of the total AUM of all synthetic ETFs in Europe (Vanguard, 2013). The data on synthetic funds have been retrieved from the db X-trackers website (www.etf.db.com). Our dataset includes both synthetic ETFs based on funded swaps and on unfunded swaps and they account for quite similar AUM ( $\$ 20.1$ billion vs. $\$ 17.8$ billion). It is also important to notice that a significant fraction of the synthetic funds (30 funds and $5.1 \%$ of AUM) are inverse funds that deliver the inverse performance of an index.

In terms of asset class, the majority of the synthetic ETFs are equity funds $(74.5 \%$ of AUM). Besides equity, other funds allow investors to be exposed to government bonds (11\%), treasuries and commercial papers (6.6\%), commodities (3.8\%), hedge funds $(2.2 \%)$, credit $(0.7 \%)$, corporate bonds $(0.6 \%)$, and currencies $(0.3 \%)$. In that sense, our sample is representative of the entire ETF industry as the share of equity ETFs is around $70 \%$ and that of fixed-income funds, commodity funds, and currency funds are $18 \%, 11 \%$, and $0.3 \%$, respectively (BlackRock, 2012).

As shown in Table 1, the sample of physical ETFs is more than twice as large as the synthetic one ( $\$ 77.5$ billion vs. $\$ 37.9$ billion of AUM). The data on physical ETFs have been collected from the iShares website (www.ishares.com). Similar to the synthetic ETF dataset, physical funds mainly track equity indices (around $70 \%$ of AUM) and government bond indices (around 10\%). However, corporate bond funds represent close to $20 \%$ of the aggregate AUM of physical funds. Furthermore, the physical fund sample is primarily made of funds that track European indices (47.6\% of AUM) and world indices (24.9\%).

\footnotetext{
${ }^{5}$ We only consider funds for which we have a complete history of weekly collateral data (see Section 3.2) and at least one year of data for the ETF price and its index.
} 


\subsection{Collateral Portfolios}

Allegations were recently made about the poor collateralization of ETFs. For instance, the Financial Stability Board (2011, page 4) states: "the synthetic ETF creation process may be driven by the possibility for the bank to raise funding against an illiquid portfolio [...] the collateral basket for a S\&PP 500 synthetic ETF could be less liquid equities or low or unrated corporate bonds in an unrelated market."

To formally test for the validity of these allegations, we collect for each sample fund the composition and the value of its collateral portfolio with a weekly frequency between July 5 , 2012 and November 29, 2012. The collateral data have been retrieved from the db X-trackers and iShares websites but because the websites keep no historical data, we had to download the collateral data for each fund, every week over our sample period. Then for each security used as collateral, we obtain its historical daily prices from Datastream. ${ }^{6}$

In Table 2, we see that the aggregate size of all collateral portfolios is equal to $\$ 40.9$ billion for synthetic ETFs, which indicates that, on average, the funds included in our analysis are overcollateralized (AUM is $\$ 37.9$ billion). For a given synthetic fund, the value-weighted average level of collateralization is $108.4 \%$. In total, there are 3,299 different securities that are used as collateral in the synthetic ETF sample, which leads to 81 collateral securities per fund on average. We notice that the number of securities is much higher for equity (around 100 securities per fund) than for fixed-income funds (10 to 20 securities per fund).

The situation is fairly different for physical funds as only a fraction of the AUM needs to be collateralized, namely the part that is loaned out. On any given day, a typical fund

\footnotetext{
${ }^{6}$ For bonds, we use the returns of the bond index that best matches the attributes of the bonds: its type (sovereign vs. corporate), country, rating, and maturity.
} 
lends $7.5 \%$ of its AUM on the securities lending market but the maximum value in our sample is $94.3 \%$ (the average of the maximum lending ratios is $18.5 \%$ ). We also notice that securities lending is more important in government bond funds (17.2\%) than in equity funds $(6.5 \%)$ or corporate bond funds $(6 \%)$. Similar to synthetic funds, physical funds are also overcollateralized, with collateral value accounting for $109.1 \%$ of the values of the lent securities. The level of diversification of the collateral portfolios is even higher for physical funds as they include hundreds of different collateralized securities (355 on average).

\subsection{Match between Index and Collateral}

A criticism addressed to ETFs is the fact that the collateral may not be positively correlated with the index tracked by the fund. Indeed, when the correlation is negative, the hedge provided by the collateral is inefficient: if the index return is large and positive when the fund counterparty defaults, the value of the collateral shrinks and a collateral shortfall mechanically arises. To look at this issue empirically, we compare the index tracked by the ETF and the securities included in the collateral portfolio. In Panel A of Table 3, we notice that for synthetic funds most of the collateral is made of equities: when measured in value, equities account for around $75 \%$ of the collateral vs. $20 \%$ for government bonds and $5 \%$ for corporate bonds. An important finding in this panel is that there is a good match between the index tracked and the collateral as $92.5 \%$ of equity ETFs are backed with equity and 96.5\% of government bonds ETFs are collateralized with government bonds. The match is also pretty good for funds that track European indices as $71.8 \%$ of the collateral are made of securities issued by European firms. ${ }^{7}$

\footnotetext{
${ }^{7}$ To understand the predominant role played by European collateral, which we dub "collateral home bias", one needs to understand the origin of the pledged collateral. Indeed, these securities come from the books
} 
Our empirical results also have some implications for the debate on the alleged regulatory arbitrage of the banks that act as swap counterparties. As previously mentioned, international agencies claim that banks primarily post assets that require more regulatory capital, such as less liquid and more risky assets. The high fraction of equities and the presence of corporate bonds in collateral portfolios are suggestive of banks strategically using collateral to minimize their regulatory capital as both equities and corporate bonds are high risk-weighted asset classes.

The situation for physical ETFs in Panel B of Table 3 contrasts sharply with the one of synthetic ETFs. Indeed, iShares mainly receives equities as collateral as they account for $97.2 \%$ of the posted collateral. As a result, the match between the index and the collateral is very high for equity funds (98.8\%) but much lower for government bond funds $(9.9 \%)$ and corporate bond funds (0\%). Another strong feature of the collateral used by iShares is the predominant role played by equities issued by Asian (almost exclusively Japanese) companies, which account for more than half of the value of the posted collateral.

To get a better sense of the type of securities used as collateral, we conduct in the Appendix an in-depth analysis of all collateralized equities (Table A1) and of all collateralized bonds (Table A2). Because they attract most critics from regulators, we focus on synthetic ETFs. The main findings about collateralized equities are that (1) they are mainly issued by large, European, non-financial firms; (2) they exhibit good liquidity on average, with low bid-ask spreads and high trading volume; (3) they have a higher beta with respect to the ETF than with respect to the stock return of Deutsche Bank, which is the swap counterparty

of the swap counterparty, typically a large financial institution. In our sample, the swap counterparty is Deutsche Bank and as a result, its books predominantly include securities issued by local firms held for investment purposes, market making, or other intermediation activities. 
for all ETFs. As for collateralized bonds, we find that (1) they predominantly come from European issuers (88.3\%); (2) two-third of the bonds have a AAA rating; (3) the interest rate duration of the collateral portfolios matches well with the duration of the fixed-income index tracked by the fund.

Now that we have documented the level and nature of ETF collateral, we are going to estimate in the following section counterparty risk exposures and test whether investors care about this source of risk.

\section{Counterparty Risk Analysis}

\subsection{Theoretical Framework}

In any ETF structure, the counterparty risk borne by the ETF issuer, and ultimately the investors, is equivalent to the risk that the ETF is not fully collateralized at the point of default by the counterparty. If we denote by $I_{t}$, the NAV of the fund at time $t, \beta_{t} \in[0,1]$ the fraction of the securities that are lent, $C_{t}$ the value of the collateral per share, and $h$ the haircut, the collateral shortfall, denoted $\Delta_{t}$, corresponds to:

$$
\Delta_{t}=\beta_{t} I_{t}-C_{t}(1-h)
$$

where $\beta_{t} \in[0,1]$ and $h>0$ for physical ETFs, $\beta_{t}=1$ and $h=0$ for unfunded-swap based ETFs, and $\beta_{t}=1$ and $h>0$ for funded-swap based ETFs. If $\Delta_{t}>0$, additional collateral is required to reach $\beta_{t} I_{t}=C_{t}(1-h)$ (Morningstar, 2012). On a given date $t$, the one-day ahead collateral shortfall $\Delta_{t+1}$ is defined as:

$$
\Delta_{t+1}=\beta_{t} I_{t}\left(1+r_{i, t+1}\right)-C_{t}(1-h)\left(1+r_{c, t+1}\right)
$$


where $r_{i, t+1}$ and $r_{c, t+1}$ denote the return of the NAV and the return of the collateral portfolio, respectively. Given the information available at time $t$, the collateral shortfall $\Delta_{t+1}$ is stochastic because the returns $r_{i, t+1}$ and $r_{c, t+1}$ are unknown.

By analogy with the credit risk literature, we consider both the default probability of the counterparty and the loss given default. In our framework, the default probability concerns the short seller (for physical ETFs) or the swap counterparty (for synthetic ETFs):

$$
P_{t+1}=\operatorname{Pr}\left(D_{t+1}=1\right)
$$

where $D_{t+1}$ takes a value of one when the fund counterparty is in default and zero otherwise. We note that the default probability does not depend on the collateralization of the fund and can be estimated using standard techniques, such as structural models or CDS spreads. The loss given default corresponds to the magnitude of the expected collateral shortfall:

$$
S_{t+1}=\mathbb{E}\left(\Delta_{t+1} \mid \Delta_{t+1}>0, D_{t+1}=1\right)
$$

where $\mathbb{E}$ denotes the conditional expectation on the information set $\mathcal{F}_{t}$ available at time $t$. This metric, which corresponds to the collateral shortfall a fund is expected to experience conditionally on the default of the counterparty, has several attractive features. First, given its conditional nature, it only focuses on concerning situations where a counterparty default and a collateral shortfall jointly occur. Second, it measures the changes in collateral value when the counterparty is in default and, as such, captures the dependence between the liquidity of the collateral and the creditworthiness of the counterparty. Third, it is a sufficient risk measure if one aims to compare the counterparty risk exposure of funds having the same counterparty, hence the same $P_{t+1}$. As this is our goal here, we focus in the rest of our analysis on expected collateral shortfall. 


\subsection{Empirical Estimates}

We estimate for each of the 164 synthetic ETFs its counterparty risk measure, $S$, with a one-day horizon. To estimate the counterparty risk metrics, we define $\omega_{t}=\left(\omega_{1, t}, \ldots, \omega_{K, t}\right)$, the vector of the weights associated with the $K$ assets that comprise the collateral portfolio of a fund at time $t$, with $\sum_{k=1}^{K} \omega_{k, t}=1$. Given Equation (2), the collateral shortfall at time $t+1$ can be written as:

$$
\Delta_{t+1}=\beta_{t} I_{t}\left(1+r_{i, t+1}\right)-C_{t}(1-h)\left(1+\sum_{k=1}^{K} \omega_{k, t} r_{k, t+1}\right)
$$

where $r_{k, t+1}$ is the daily return of the $k$-th collateral security at time $t+1$. Given the information set $\mathcal{F}_{t}$, the potential collateral shortfall at time $t+1$ only depends on $r_{i, t+1}$ and $r_{k, t+1}$ for $k=1, \ldots, K$.

One way to estimate the expected collateral shortfall is to assume a given distribution for these returns and to derive closed-form expressions for $S$. Alternatively, we use a simple nonparametric estimation method. Following Berkowitz and O'Brien (2002), we consider a series of hypothetical collateral shortfalls:

$$
\Delta_{\tau}=\beta_{t} I_{t}\left(1+r_{i, \tau}\right)-C_{t}(1-h)\left(1+\sum_{k=1}^{K} \omega_{k, t} r_{k, \tau}\right)
$$

where $r_{i, \tau}$ is the historical daily return of the NAV, for $\tau=1, \ldots, t$ and $r_{k, \tau}$ is the daily return

of the $k$-th collateral security at time $\tau$. The hypothetical collateral shortfall $\Delta_{\tau}$ measures the shortfall that would have arisen in the past with the current values of $I_{t}, C_{t}$, and $\omega_{t}$, and the past returns on the NAV and on the collateral securities. However, as the counterparty in our sample never actually defaulted in the past, we estimate the counterparty risk metrics using past observations from a high counterparty-risk regime, i.e., a period during which 
the counterparty experienced a sharp increase in its default probability. A nonparametric estimator for the expected collateral shortfall is:

$$
\widehat{S}_{t+1}=\frac{\sum_{\tau=1}^{t} \Delta_{\tau} \times \mathbb{I}\left(\Delta_{\tau}>0\right) \times \mathbb{I}(\tau \in \bar{\Upsilon})}{\sum_{\tau=1}^{t} \mathbb{I}\left(\Delta_{\tau}>0\right) \times \mathbb{I}(\tau \in \bar{\Upsilon})}
$$

where $\mathbb{I}($.$) denotes the indicator function and \bar{\Upsilon}$ denotes a high-counterparty risk regime. In our tests, the high counterparty-risk regime corresponds to the two-month period around the bankruptcy of Lehman Brothers (September 1, 2008 - October 31, 2008). Over these two months, the CDS-implied default probability of the swap counterparty, Deutsche Bank, got multiplied by three, and its market capitalization dropped by $50 \%$.

In Table 4, we display the distribution of the expected collateral shortfall, expressed alternatively as a percentage of the NAV and in dollars, for all synthetic funds. For each fund, the risk metrics are averaged across time. The main result in this figure is that counterparty risk exposure varies extensively across funds. While the expected shortfall remains for most funds below $5 \%$ of the NAV, some of them exhibit an expected collateral shortfall that corresponds to one third of their NAV.

As a comparison, we conduct a similar risk assessment for physical ETFs as they also expose their investors to counterparty risk through securities lending. It is indeed possible that the short sellers who borrow securities from the ETF issuer fail to return them in due time. We see in Table 4 that the difference in risk exposure is striking: counterparty risk exposure is several orders of magnitude higher for synthetic ETF investors. 


\subsection{Trade-off between Risk and Performance}

We have seen that synthetic-ETFs' investors tend to be more exposed to counterparty risk than physical-ETFs' investors. A natural question is whether the former investors are compensated for bearing this additional risk. We answer this question by considering two important dimensions of an ETF: its costs and its tracking error. In particular, we formally show that synthetic ETFs are as cheap or cheaper and display better performance (i.e., lower tracking error) than physical ETFs. ${ }^{8}$ As a result, synthetic funds' investors are compensated for bearing this additional risk by enjoying superior performance for the same price.

We conduct this test in two ways. In Panel A of Table 5, our unconditional tests reveal no clear difference between the fees charged by synthetic and physical funds. ${ }^{9}$ The average fee for physical ETFs are 44 bps vs. 43 bps for synthetic ETFs. However, we find major differences in the tracking error of these funds: the average tracking error is 96 bps for physical ETFs and 13 bps for synthetic ETFs. Another interesting result is the much higher tracking error for funds that pay dividends (Distributing), which indicates that a major source of tracking error for funds is the way dividends are handled and passed through to investors.

In Panel B of Table 5, we complement these unconditional results by running multivariate regressions for, in turn, fees and tracking errors. We find that the coefficient associated with the synthetic ETF's dummy variable is negative and significant for both the fees and the tracking errors. Interestingly, we uncover that inverse funds tend to charge higher fees and

\footnotetext{
${ }^{8}$ We define the tracking error as the annualized volatility of the difference between the daily returns of the ETF and of the index.

${ }^{9}$ For an empirical analysis of the fees of active and passive (including ETFs) funds in the world, see Cremers et al. (2015).
} 
funds that distribute dividends exhibit larger tracking errors. Differently, tracking error decreases with fund size.

\subsection{Do ETF Investors Care about Counterparty Risk?}

We now turn to testing whether ETF flows are sensitive to changes in counterparty risk. We envision that it could be the case for two reasons. First, a significant fraction of all ETF trading is made by institutional investors, which are perceived as sophisticated investors, and they are able to withdraw funds quickly when they are not comfortable with the risk they face. A recent example is the run on money market funds by institutional investors following the bankruptcy of Lehman Brothers on September 15, 2008 (Schmidt, Timmermann and Wermers, 2014). Second, the creditworthiness of the swap counterparty can be monitored in real time in the CDS market.

While our fund flow data start in 2008, we believe that most investors were not aware of the counterparty risk concerns before 2011. Indeed, as mentioned in the introduction, the debate on the counterparty risk of synthetic ETFs started during the first half of 2011 when trenchant criticisms were made by international agencies and industry leaders (see quote of Laurence D. Fink on page 2). To identify the exact timing, we searched for articles in the financial press that include the words "synthetic ETF" (from the Factiva database) as well as the number of queries on Google including the keywords "synthetic ETF" (from Google Trends) between 2006 and 2015. Both proxies for market awareness remained at, or close to, zero until 2011 and then jumped to almost 300 articles and to a Google Search Index of 100.

Our setting allows us to cleanly identify, using the difference-in-differences method, the 
effect of counterparty risk on synthetic ETF outflows before and after 2011. Since we do not observe flows directly, we follow Frazzini and Lamont (2008) and Barber, Huang and Odean (2015) and infer flows from fund asset value and returns:

$$
\text { flow }_{i, t}=I_{i, t} \cdot \text { \#outstanding_shares }_{i, t}-I_{i, t-1} \cdot \text { \#outstanding_shares }_{i, t-1} \cdot\left(1+r_{i, t}\right)
$$

where $r_{i, t}$ is the return of the NAV for fund $i$ between time $t-1$ and $t$. By doing so, the performance of the fund is not taken into account as we only capture share redemptions (outflows) and share purchases (inflows). Then, we run the following difference-in-differences panel regression:

$$
\text { outflow }_{i, t}=\alpha_{i}+\beta_{1} \cdot \text { Risk }_{t-1} \cdot \text { Post }_{t}+\beta_{2} \cdot \text { Risk }_{t-1}+\beta_{3} \cdot \text { Post }_{t}+\beta_{4} \cdot \operatorname{Perf}_{i, t}+\varepsilon_{i, t}
$$

where outflow $w_{i, t}$ is either a dummy variable that takes a value of one if there is an outflow between $t-1$ and $t$ and zero otherwise (Probit model) or the log of the absolute outflow and zero if there is an inflow (Tobit model). Risk $k_{t-1}$ is a dummy variable equal to one if the CDS spread of the swap counterparty at time $t-1$ is greater than the 75 th percentile of its distribution, Post $t_{t}$ is a dummy variable that takes a value of one after June 2011, and $\operatorname{Perf}_{i, t}$ is the return of the index tracked by the fund a time $t$.

We estimate a Probit specification of Equation (9) using monthly data on all synthetic funds over the period August 2008-December 2013 and report the results in the first two columns of Table 6. This difference-in-differences identification allows us to compare synthetic funds in high-risk states after June 2011 ("treated") to synthetic funds in low-risk states as well as synthetic funds before June 2011 ("control"). Our main finding is that the estimated $\beta_{1}$ parameter is positive and significant. This suggests that once investors 
became aware of this additional source of risk in 2011, more counterparty risk triggered more outflows from synthetic ETFs. This result is robust across funds from different asset classes as shown in columns 1 and 2 (equity only vs. all exposures). Interestingly, we also report a negative relationship between the performance of the index tracked by the fund and the probability of observing an outflow, which is consistent with standard findings from the mutual fund literature about return-chasing investors (Chevalier and Ellison, 1997; Carhart, 1997). Furthermore, the probability of having an outflow increased significantly for synthetic funds after counterparty risk concerns became public information $\left(\widehat{\beta}_{3}>0\right.$ and significant). While our findings are based on a single issuer, they turn out to be consistent with a recent trend in the entire industry. According to figures from consultancy firm ETFGI, the size of the synthetic segment of the European ETF industry has experienced continuous growth since 2006 but it shrank dramatically in 2011 with a $\$ 23$ billion drop in AUM.

We obtain similar results when we consider a larger control group which also includes physical funds (column 3). We extend Equation (9) by including an extra dummy variable (Syn) for synthetic funds, which also interacts with Risk and Post. In column 3, the estimated parameter $\widehat{\beta}_{1}$ associated with the interaction terms (now triple) remains positive. The fact that this parameter remains positive indicates that the results in the first two columns are unlikely to be due to omitted factors (e.g. market stress during European debt crisis of 2012) that would impact outflows after June 2011. Indeed, such factors should also impact outflows for physical ETFs, which are now part of the control group. We also notice that the probability to face outflows is lower for synthetic ETFs, which is consistent with the fact that our sample period includes the take-off of the synthetic industry that has triggered 
some important transfers from physical to synthetic funds. Another robustness check we consider is to estimate the treatment effect on the magnitude of the flows. In column 4, we estimate a Tobit model using the absolute outflows as our dependent variable and the sign of the coefficients remain unchanged. Finally, we re-estimate our four specifications by using the level of the CDS spread as the Risk variable. In all cases, we obtain qualitatively similar (unreported) results.

\section{Optimal Collateral Portfolio}

\subsection{Definitions}

In this study, we have extensively analyzed the size, composition, and performance of collateral portfolios currently used in the ETF industry. In the last part of our analysis, we check whether the performance of such collateral portfolios could be improved. To do so, we show how to construct an optimal collateral portfolio that aims to protect ETF investors against counterparty risk. With such a benchmark, we can empirically measure how much could be gained by switching from an actual collateral portfolio to the optimal one. The process that leads to the optimal collateral portfolio can be divided into three steps.

Step 1: Eligible securities The counterparty and the ETF issuer have to determine a set of eligible securities. In practice, the securities pledged as collateral directly come from the inventory of the counterparty, which includes securities held for investment purposes, market making, underwriting, or other intermediation activities. When choosing the securities to be pledged, the collateral provider might want to reduce its regulatory capital by transferring 
high risk-weight securities and/or to minimize the opportunity cost of holding collateral. ${ }^{10}$

On the receiver side, only collateral with sufficient tradability will be admitted. This interaction between the provider and the receiver of collateral leads to the determination of a set of $K$ eligible securities that need to be allocated.

Step 2: Level of collaterization Both parties have to determine the level of collateralization. At the end of day $t$, the value of the collateral portfolio $C_{t}$, adjusted by the haircut $h$, is determined by the fraction $\beta_{t}$ of the NAV $I_{t}$ which has to be collateralized and the desired level of collateralization $\alpha$ :

$$
C_{t}=\frac{\alpha \beta_{t} I_{t}}{(1-h)}
$$

If $\alpha=1$, the fund is full collateralized at time $t$. When $\alpha>1$ the value of the collateral portfolio, adjusted for haircut, is larger than the fraction $\beta_{t}$ of the NAV which has to be collateralized. By substituting $I_{t}$ from Equation (10) into Equation (11), we get:

$$
\Delta_{t+1}=C_{t}(1-h)\left(\frac{1-\alpha}{\alpha}+\frac{r_{i, t+1}}{\alpha}-\sum_{k=1}^{K} \omega_{k} r_{k, t+1}\right)
$$

Step 3: Optimal composition of the collateral portfolio Given the eligible securities and the level of collateralization on day $t$, the optimal composition of the collateral portfolio is determined by choosing the weights $\omega=\left(\omega_{1}, \ldots, \omega_{K}\right)$ to maximize the investors' expected utility on day $t+1$, defined as a decreasing function of the collateral shortfall $\Delta_{t+1}$ (see Appendix A), for $\Delta_{t+1}>0$.

\footnotetext{
${ }^{10}$ Such securities include those with relatively low fees on the securities lending market; those with relatively low collateral value in the repo market (Bartolini et al., 2011); those that are not eligible as collateral for central-bank credit operations; and securities for which the demand is low on the secondary market (Brandt and Kavajecz, 2004).
} 
Definition 1 The optimal collateral portfolio $\omega^{*}=\left(\omega_{1}^{*}, \ldots, \omega_{K}^{*}\right)^{\prime}$ at time $t$ satisfies:

$$
\begin{aligned}
\qquad \omega^{*}= & \underset{\omega \in \Theta_{t}}{\arg \max } \mathbb{E}\left[u\left(-\Delta_{t+1}\right)\right] \\
\text { subject to } & \left\{\begin{array}{l}
\omega \geq 0 \\
e^{\top} \omega=1
\end{array}\right.
\end{aligned}
$$

where $u($.$) is the utility function of the investors, \Theta_{t}$ denotes the set of all feasible portfolios based on the $K$ eligible securities, and $e$ is the unit vector.

We impose $\omega$ to be non-negative since short positions in collateral would be nonsensical. As usual, the sum of the portfolio weights is normalized to one. In practice, many other types of constraints can be considered in the program. ${ }^{11}$

When the utility function is explicitly specified, the optimal collateral portfolio can be directly obtained by solving program (12) with analytical or numerical methods. There is no particular constraint on the choice of the objective function, except that the program should be well specified and that there exists a unique optimal solution. Alternatively, in the next subsection, we derive the optimal collateral portfolio through a mean-variance approach (Markowitz, 1959), in which the investor's expected utility is a function of the mean and the variance of the collateral shortfall.

\subsection{Efficient Frontier for Collateral Portfolios}

A collateral portfolio is mean-variance efficient if it minimizes the shortfall variance $\sigma_{\Delta}^{2}(\omega)=$ $\mathbb{V}\left(\Delta_{t+1} \mid D_{t+1}=1\right)$ for a given mean $\mu_{\Delta}(\omega)=\mathbb{E}\left(\Delta_{t+1} \mid D_{t+1}=1\right)$

\footnotetext{
${ }^{11}$ One can prevent any issuer to account for more than a certain fraction of the collateral portfolio. Another constraints can be added on the liquidity of the assets selected for the collateral portfolio or on the collateral portfolio itself. For instance, the optimal weights can be determined under the constraint that the liquidity of the optimal portfolio (measured according a particular liquidity risk measure) is larger than a lower bound.
} 
Definition 2 The efficient frontier for collateral portfolios is given by all portfolios $\widetilde{\omega}(\gamma) \in$ $\bar{\Theta}_{t}$ that are solutions of the following optimization program:

$$
\begin{aligned}
\widetilde{\omega}(\gamma)= & \underset{\omega \in \bar{\Theta}_{t}}{\arg \min } \sigma_{\Delta}^{2}(\omega) \\
& \text { subject to }\left\{\begin{array}{l}
\mu_{\Delta}(\omega)=\gamma \\
\omega \geq 0 \\
e^{\top} \omega=1
\end{array}\right.
\end{aligned}
$$

where $\bar{\Theta}_{t}$ is the set of all eligible portfolios such that $\mu_{\Delta}(\omega) \leq \bar{\gamma}$ and $\bar{\gamma}$ is the mean shortfall of the Global Minimum Variance Collateral Portfolio (GMVCP), i.e., the portfolio that minimizes $\sigma_{\Delta}^{2}(\omega)$.

Both moments $\mu_{\Delta}(\omega)$ and $\sigma_{\Delta}^{2}(\omega)$ can be expressed as functions of the moments of the returns of the collateral securities and of the NAV. Define $r_{t}=\left(r_{1, t}, \ldots, r_{K, t}\right)^{\top}$ the $K \times 1$ vector of returns of the collateral securities and $z_{t}=\left(r_{i, t} / \alpha, r_{t}^{\top}\right)^{\top}$, with:

$$
\begin{gathered}
\mathbb{E}\left(z_{t+1} \mid D_{t+1}=1\right)=\left(\begin{array}{c}
\mu_{i} \\
(1,1) \\
\hline \mu \\
(K, 1)
\end{array}\right) \\
\Sigma_{z}=\mathbb{E}\left(\left(z_{t+1}-\mathbb{E}\left(z_{t+1}\right)\right)\left(z_{t+1}-\mathbb{E}\left(z_{t+1}\right)\right)^{\top} \mid D_{t+1}=1\right)=\left(\begin{array}{c|c}
\sigma_{i}^{2} & \sum_{i}^{\top} \\
(1,1) & (1, K) \\
\hline \Sigma_{i} & \Sigma_{(K, K)} \\
(K, 1) & (K, K)
\end{array}\right)
\end{gathered}
$$

where $\mu_{i}$ and $\sigma_{i}^{2}$ respectively denote mean and variance of $r_{i, t} / \alpha$. Without loss of generality, we assume that $C_{t}(1-h)=1$ and express the program in Equation (13) as:

$$
\begin{array}{r}
\widetilde{\omega}(\gamma)=\underset{\omega \in \bar{\Theta}_{t}}{\arg \min } \frac{1}{2} \omega^{\top} \Sigma \omega+\frac{1}{2} \sigma_{i}^{2}-\omega^{\top} \Sigma_{i} \\
\text { subject to }\left\{\begin{array}{l}
\mu_{i}-\omega^{\top} \mu=\widetilde{\gamma} \\
\omega \geq 0 \\
e^{\top} \omega=1
\end{array}\right.
\end{array}
$$

with $\widetilde{\gamma}=\gamma-(1-\alpha) / \alpha$, for all $\gamma \leq \bar{\gamma}$. The associated Lagrange function $f\left(\omega, \lambda_{1}, \lambda_{2}, \lambda_{3}\right)$ is:

$$
f\left(\omega, \lambda_{1}, \lambda_{2}, \lambda_{3}\right)=\frac{1}{2} \omega^{\top} \Sigma \omega+\frac{1}{2} \sigma_{i}^{2}-\omega^{\top} \Sigma_{i}-\lambda_{1}\left(e^{\top} \omega-1\right)-\lambda_{2}\left(\omega^{\top} \mu-\mu_{i}+\widetilde{\gamma}\right)-\lambda_{3}^{\top} \omega
$$


with $\lambda_{1}>0, \lambda_{2}>0$ and $\lambda_{3, i} \geq 0$ for $i=1, \ldots, K$. When the positivity constraints are not binding $\left(\lambda_{3}=0\right)$, the weights of the portfolios that belong to the efficient frontier can be expressed as a function of the weights of the Markowitz's mean variance efficient portfolios. ${ }^{12}$ We define three scalars $a, b$, and $c$ such that:

$$
a=e^{\top} \Sigma^{-1} e \quad b=e^{\top} \Sigma^{-1} \mu \quad c=\mu^{\top} \Sigma^{-1} \mu
$$

where $e$ is the unit vector.

Proposition 1 If $\lambda_{3}=0$, the weights of the efficient portfolios are defined by:

$$
\widetilde{\omega}(\gamma)=\widetilde{\omega}_{M V}+\Sigma^{-1} \Sigma_{i}+\left(\frac{c e^{\top}-b \mu^{\top}}{b^{2}-a c}\right) \Sigma^{-1} \Sigma_{i} \Sigma^{-1} e+\left(\frac{a \mu^{\top}-b e^{\top}}{b^{2}-a c}\right) \Sigma^{-1} \Sigma_{i} \Sigma^{-1} \mu
$$

where $\widetilde{\omega}_{M V}$ corresponds to the weights of the Markowitz's mean-variance efficient portfolios:

$$
\widetilde{\omega}_{M V}=\left(\frac{b \mu_{i}-b \widetilde{\gamma}-c}{b^{2}-a c}\right) \Sigma^{-1} e+\left(\frac{b-a \mu_{i}+a \widetilde{\gamma}}{b^{2}-a c}\right) \Sigma^{-1} \mu
$$

and $\widetilde{\gamma}=\gamma-(1-\alpha) / \alpha$.

The proof of Proposition 1 is provided in Appendix B. The efficient weights depend on $\Sigma$ and $\Sigma_{i}$, but they also depend on the vector of expected returns of the collateral securities $\mu$ and on the expected transformed return of the NAV $\mu_{i}-\widetilde{\gamma}$. The latter can be viewed as a target for the expected return of the collateral portfolio, $\omega^{\top} \mu$. Notice that if the collateral securities and the NAV are independent, $\Sigma_{i}=0_{K \times 1}$, then the efficient weights simply correspond to the weights $\widetilde{\omega}_{M V}$ of the mean-variance portfolio with a target mean $\mu_{i}-\widetilde{\gamma}$

\footnotetext{
${ }^{12}$ When at least one asset $k \in\{1, \ldots, K\}$ is excluded from the optimal portfolio, i.e., for which $\lambda_{3, k}>0$ and $\omega_{k}=0$, there is no closed-form solution for the optimal constrained portfolio. However, the solution of the program can be obtained by solving the unconstrained problem with an implied covariance matrix $\widetilde{\Sigma}$ defined as a shrunk version of $\Sigma$ that depends on the Lagrange coefficients (Jagannathan and Ma, 2003).
} 
Finally, the optimal portfolio $\omega^{*}$ is determined by choosing from the mean-variance efficient portfolios $\widetilde{\omega}(\gamma)$ for $\gamma \leq \bar{\gamma}$, the portfolio with the highest expected utility. An alternative solution consists in choosing the portfolio that minimizes the non-parametric estimate of the expected collateral shortfall $\widehat{S}_{t+1}($ Equation 7$)$. The latter estimation strategy has the advantage of not imposing a particular utility function for the investors, neither any distributional assumptions for the returns.

\subsection{Actual vs. Optimal Collateral}

We compare actual and optimal collateral portfolios for a sample of total return swaps associated with some of the largest ETFs in our sample. The funds track respectively the DAX index (equity), the Eurostoxx 50 index (equity), the iBoxx Global Inflation-Linked index (Treasuries), and the iBoxx Sovereigns Eurozone index (Treasuries). On the last day of our sample period (November 29, 2012), the assets under management (AUM) of these funds range between $\$ 600$ million for the iBoxx Sovereigns fund and $\$ 8.5$ billion for the DAX fund and the total return swaps associated are either fully collateralized or almost fully collateralized.

The composition of the collateral portfolios is described in Panel A of Table 7. The actual collateral portfolios of the sample ETFs include a total of 81 securities. The set of securities used as collateral for these four ETFs includes 47 equities and 34 government bonds. The number of posted securities in each portfolio ranges from 9 for the iBoxx Sovereigns Eurozone swap to 31 to the DAX swap. Besides the 81 securities included in the four collateral portfolios, we also know the identity of another 1,436 securities that are included, on the same day, in the collateral portfolios of another 160 ETFs managed by db-X trackers. This 
pool of $K=1,517(=81+1,436)$ securities can be interpreted as the set $\Theta_{t}$ of eligible collateral securities (see Panel B). We note that the majority of the used collateral securities are equities: 1,438 out of 1,517 vs. 62 government bonds and 27 corporate bonds.

For each sample swap, we estimate the efficient collateral frontier and then pick the optimal portfolio associated with the lowest expected collateral shortfall, which is estimated non-parametrically. The covariance matrix $\Sigma$ is estimated from asset returns observed during a high counterparty-risk regime (September 1, 2008 - October 31, 2008). As the number of collateral securities is larger than the number of dates in the high counterparty-risk regime, the sample covariance matrix suffers from a small sample size problem and ends up being singular. To alleviate this problem, we use the shrinkage estimator of the covariance matrix $\Sigma_{z}$ proposed by Ledoit and Wolf (2003). The estimators of the expected returns $\mu_{i}$ and $\mu$ are defined by their empirical counterparts over the same period. The numerical solution for the mean-variance frontier, with positivity constraints, is obtained using CVX, a package for specifying and solving convex problems (Grant and Boyd, 2008).

Figure 2 displays the mean-variance efficient frontier, along with the actual and optimal collateral portfolios, for the swap on the Euro Stoxx 50 index. As the actual collateral portfolio does not lie on the frontier, switching to the optimal portfolio would allow investors to reduce both the mean and the variance of the collateral shortfall, hence reducing their counterparty risk exposure.

Panel A of Table 7 compares the actual and optimal portfolios for the four ETFs. We observe that the total number of securities included in the collateral portfolios are quire similar (81 in the actual portfolios vs. 156 in the optimal portfolios) but that optimal portfolios 
are more tilted towards equities than bonds. For each fund, the optimal number of securities ranges between 36 and 71 securities, which is slightly larger than actual portfolios (between 9 and 31). However, as the optimization is based on a universe of around 1,500 securities, these findings illustrate the relative concentration of the optimal collateral portfolios and suggests that our approach leads to realistic portfolios. More importantly, optimal portfolios are characterized by lower counterparty risk exposure: the expected collateral shortfall $S_{t+1}$ reduces by $29 \%$ for the equity ETFs (27.38\% for the DAX and $30.39 \%$ for the Eurostock) and by $17 \%$ for the bond ETFs $(16.84 \%$ for the global inflation index and $16.67 \%$ for the sovereign index). This is evidence that active collateral management can greatly reduce the counterparty risk associated with passive investment vehicles.

\section{Conclusion}

How safe are ETFs? We show in this paper that the answer to this question very much depends on the collateral management policy of the fund issuers. We study the collateral portfolios of ETFs that are based on swaps or engage in securities lending, hence exposing their investors to counterparty risk. We find that funds tend to be overcollateralized and that collateral mainly consists of equities and to a lesser extent highly rated bonds.

There is some heterogeneity in the level of counterparty risk exposure of ETF investors. Risk exposure is shown to be higher for inverse ETFs which deliver the inverse performance of the underlying index. We also find that counterparty risk exposure is higher for synthetic ETFs but that investors are compensated for bearing this risk. Using a differencein-differences specification, we show that ETF flows respond significantly to changes in counterparty risk, which suggests that investors closely monitor their counterparty risk exposure. 
Our findings on the importance of counterparty risk for ETF investors have been corroborated by a recent change in business models for several leading asset managers. Given investors' growing distrust in synthetic replication, Lyxor and db X-trackers, two long-time proponents of synthetic ETFs, both decided to switch some of their largest funds to physical replication (Financial Times, 2014). 


\section{References}

[1] Bai, Q., S. A. Bond, and B. Hatch (2012) The Impact of Leveraged and Inverse ETFs on Underlying Stock Returns, Working Paper.

[2] Barber, B. M., X. Huang, and T. Odean (2015) Which Risk Factors Matter to Investors? Evidence from Mutual Fund Flows, Working Paper.

[3] Bartolini, L., S. Hilton, S. Sundaresan, and C. Tonetti (2011) Collateral Values by Asset Class: Evidence from Primary Securities Dealers, Review of Financial Studies, $24,248-278$.

[4] Ben-David, I. , F. A. Franzoni, and R. Moussawi (2014) Do ETFs Increase Volatility?, Working Paper.

[5] Berkowitz, J. and J. O'Brien (2002) How Accurate Are Value-at-Risk Models at Commercial Banks?, Journal of Finance, 57, 1093-1111.

[6] Bessembinder, H. (2015) Predictable ETF Order Flow and Market Quality, Journal of Trading, 10, 17-23.

[7] Bessembinder, H., A. Carrion, L. Tuttle, and K. Venkataraman (2015) Liquidity, Resiliency and Market Quality Around Predictable Trades: Theory and Evidence, Journal of Financial Economics, forthcoming.

[8] BlackRock (2012) ETP Landscape, November.

[9] BlackRock (2015) ETP Landscape, October.

[10] Blocher J. and R. E. Whaley (2015) Passive Investing: The Role of Securities Lending, Working Paper.

[11] Bloomberg (2011) BlackRock's Fink Attacks Societe Generale Over ETF Risks, November 17 .

[12] Boyson, N., C. W. Stahel, and R. M. Stulz (2010) Hedge Fund Contagion and Liquidity Shocks, Journal of Finance, 55, 1789-1816.

[13] Brandt, M. and K. Kavajecz (2004) Price Discovery in the U.S. Treasury Market: The Impact of Order Flow and Liquidity on the Yield Curve, Journal of Finance, 59, 26232654 .

[14] Carhart, M. (1997) On Persistence in Mutual Fund Performance, Journal of Finance, $52,57-82$.

[15] Célérier C. and B. Vallée (2015) Catering to Investors through Products Complexity, Working Paper. 
[16] Chen, Y. (2011) Derivatives Use and Risk Taking: Evidence from the Hedge Fund Industry, Journal of Financial and Quantitative Analysis, 46, 1073-1106.

[17] Chen, Q., I. Goldstein, and W. Jiang (2010) Payoff Complementarities and Financial Fragility: Evidence from Mutual Fund Outflows, Journal of Financial Economics, 97, 239-262.

[18] Chevalier, J. A. and G. D. Ellison (1997) Risk Taking by Mutual Funds as a Response to Incentives, Journal of Political Economy, 105, 1167-1200.

[19] Coval, J. and E. Stafford (2007) Asset Fire Sales (and Purchases) in Equity Markets, Journal of Financial Economics, 86, 479-512.

[20] Cremers, M., M. A. Ferreira, P. Matos, and L. Starks (2015) Indexing and Active Fund Management: International Evidence, Journal of Financial Economics, forthcoming.

[21] Da, Z. and S. Shive (2013) When the Bellwether Dances to Noise: Evidence from Exchange-Traded Funds, Working Paper.

[22] Dannhauser, C. D. (2014) The Equitization of the Corporate Bond Market: The Impact of ETFs on Bond Yields and Liquidity, Working Paper.

[23] Financial Stability Board (2011) Potential Financial Stability Issues Arising from Recent Trends in Exchange-Traded Funds (ETFs).

[24] Financial Times (2014) Lyxor Extends Physical ETF Push, June 17, 2014.

[25] Frazzini, A. and O. A. Lamont (2008) Dumb Money: Mutual Fund Flows and the Cross-Section of Stock Returns, Journal of Financial Economics, 88, 299-322.

[26] Grant, M. and S. Boyd (2008) Graph implementations for nonsmooth convex programs, Recent Advances in Learning and Control, Ed. by V. Blondel, S. Boyd, and H. Kimura, Springer, 95-110.

[27] Hamm, S. J. W. (2014) The Effect of ETFs on Stock Liquidity, Working Paper.

[28] International Monetary Fund (2011) Global Financial Stability Report, 68-72.

[29] Ivanov, I. T., and S. L. Lenkey (2014) Are Concerns about Leveraged ETFs Overblown?, Working Paper, Board of Governors of the Federal Reserve System.

[30] Jagannathan, R. and T. Ma (2003) Risk Reduction in Large Portfolios: Why Imposing the Wrong Constraints Helps, Journal of Finance, 58, 1651-1684.

[31] Jotikasthira, C., C. Lundblad, and T. Ramadorai (2012) Asset Fire Sales and Purchases and the International Transmission of Funding Shocks, Journal of Finance, 67, 20152050 . 
[32] Kacperczyk, M. T. and P. Schnabl (2013) How Safe are Money Market Funds?, Quarterly Journal of Economics, 128, 1073-1122.

[33] Koski, J. L. and J. Pontiff (1999) How Are Derivatives Used? Evidence from the Mutual Fund Industry, Journal of Finance, 54, 791-816.

[34] Ledoit, O. and M. Wolf (2003) Improved Estimation of the Covariance Matrix of Stock Returns with an Application to Portfolio Selection, Journal of Empirical Finance, 10, 603-621.

[35] Malamud, S. (2015) A Dynamic Equilibrium Model of ETFs, Working Paper.

[36] Markowitz, H. M. (1959) Portfolio Selection: Efficient Diversification of Investments, Wiley, Yale University Press.

[37] Mitchell, M., L. H. Pedersen, and T. Pulvino (2007) Slow Moving Capital, American Economic Review, 97, 215-220.

[38] Morningstar (2012) Synthetic ETFs under the Microscope: A Global Study.

[39] Ramaswamy, S. (2011) Market Structures and Systemic Risks of Exchange-Traded Funds, Working Paper, Bank for International Settlements.

[40] Schmidt, L. D. W., A. G. Timmermann, and R. Wermers (2014) Runs on Money Market Mutual Funds, Working Paper.

[41] Shum, P. M., W. Hejazi, E. Haryanto, and A. Rodier (2014) Intraday Share Price Volatility and Leveraged ETF Rebalancing, Working Paper, York University and University of Toronto.

[42] Tang, H. and X. E., Xu (2013) Solving the Return Deviation Conundrum of Leveraged Exchange-Traded Funds, Journal of Financial and Quantitative Analysis, 48, 309-342.

[43] Tuzun, T. (2014) Are Leveraged and Inverse ETFs the New Portfolio Insurers?, Working Paper.

[44] Vanguard (2013) Understanding Synthetic ETFs, June. 


\section{Figure 1 - ETF Structures}

Panel A: Physical ETF

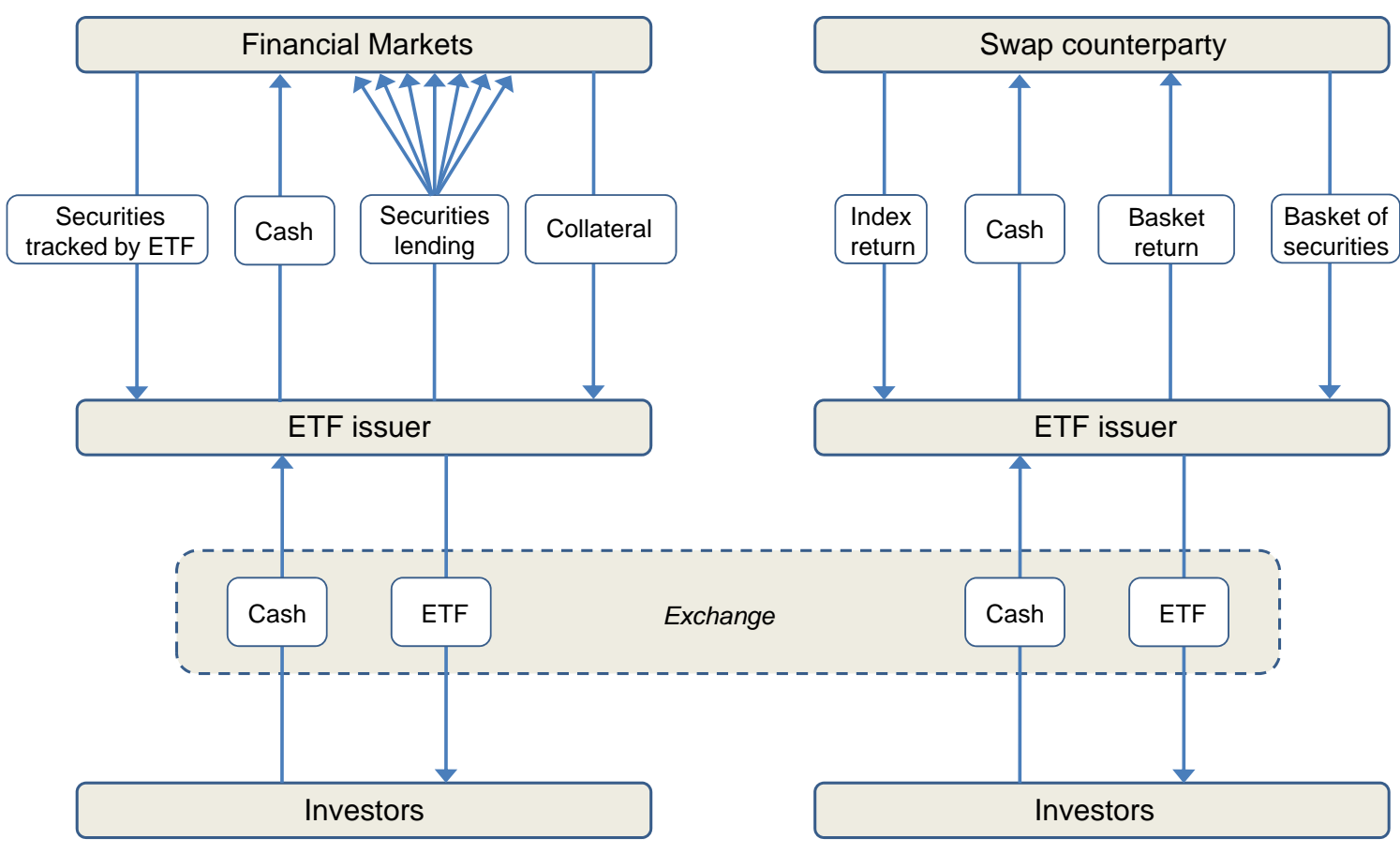

Notes: This figure describes the different cash-flows and asset transfers for two ETF structures: the physical ETF (Panel A) and the swap-based or synthetic ETF (Panel B). 
Figure 2 - Efficient Collateral Frontier for the Euro Stoxx 50 ETF

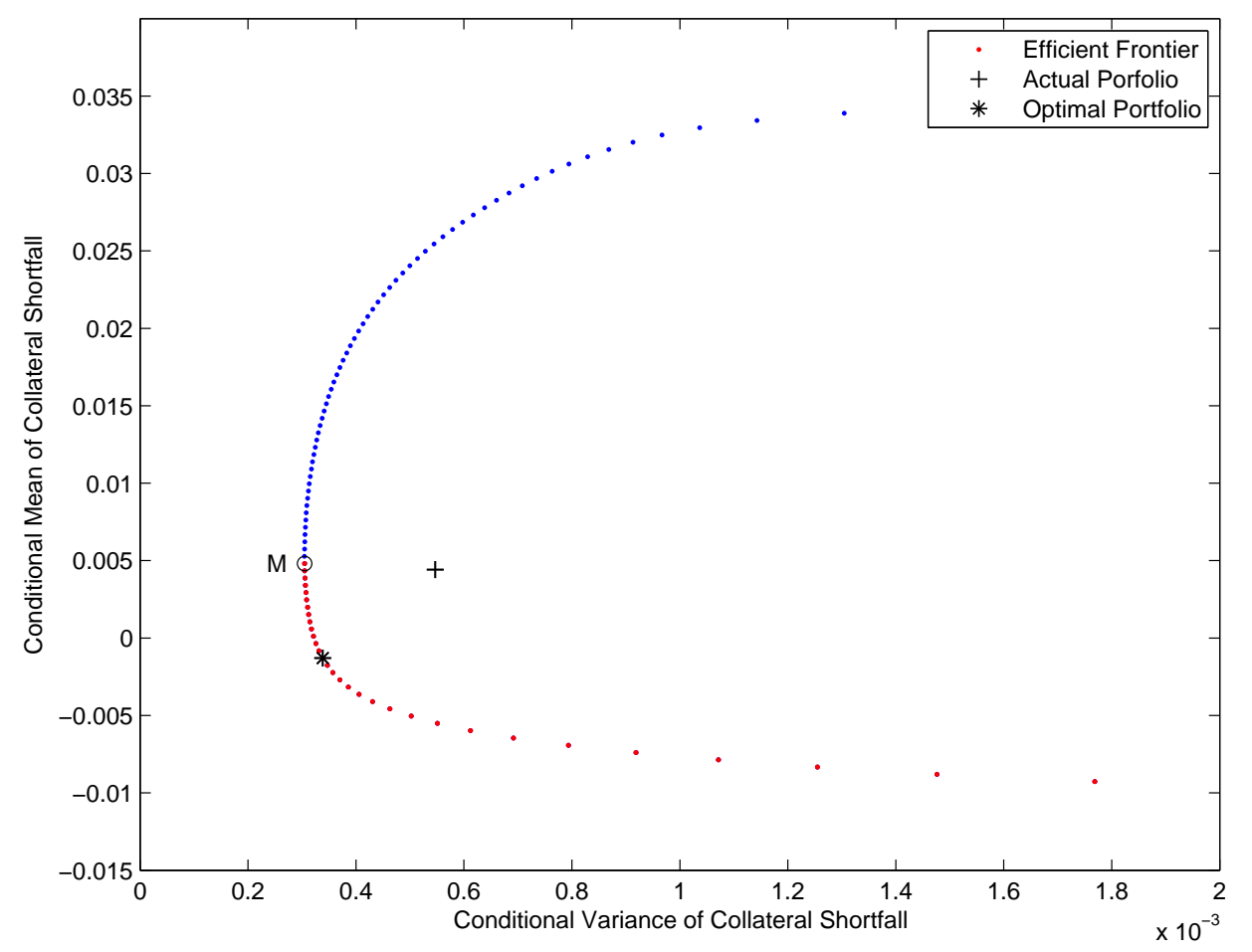

Notes: This figure presents the efficient frontier (in red), as well as the actual and the optimal collateral portfolio for the Euro Stoxx $50 \mathrm{ETF}$, on November 29, 2012. The minimum variance portfolio M is also displayed. For both the mean (y-axis) and the variance (x-axis), the collateral shortfalls are expressed relative to the NAV of the fund. 


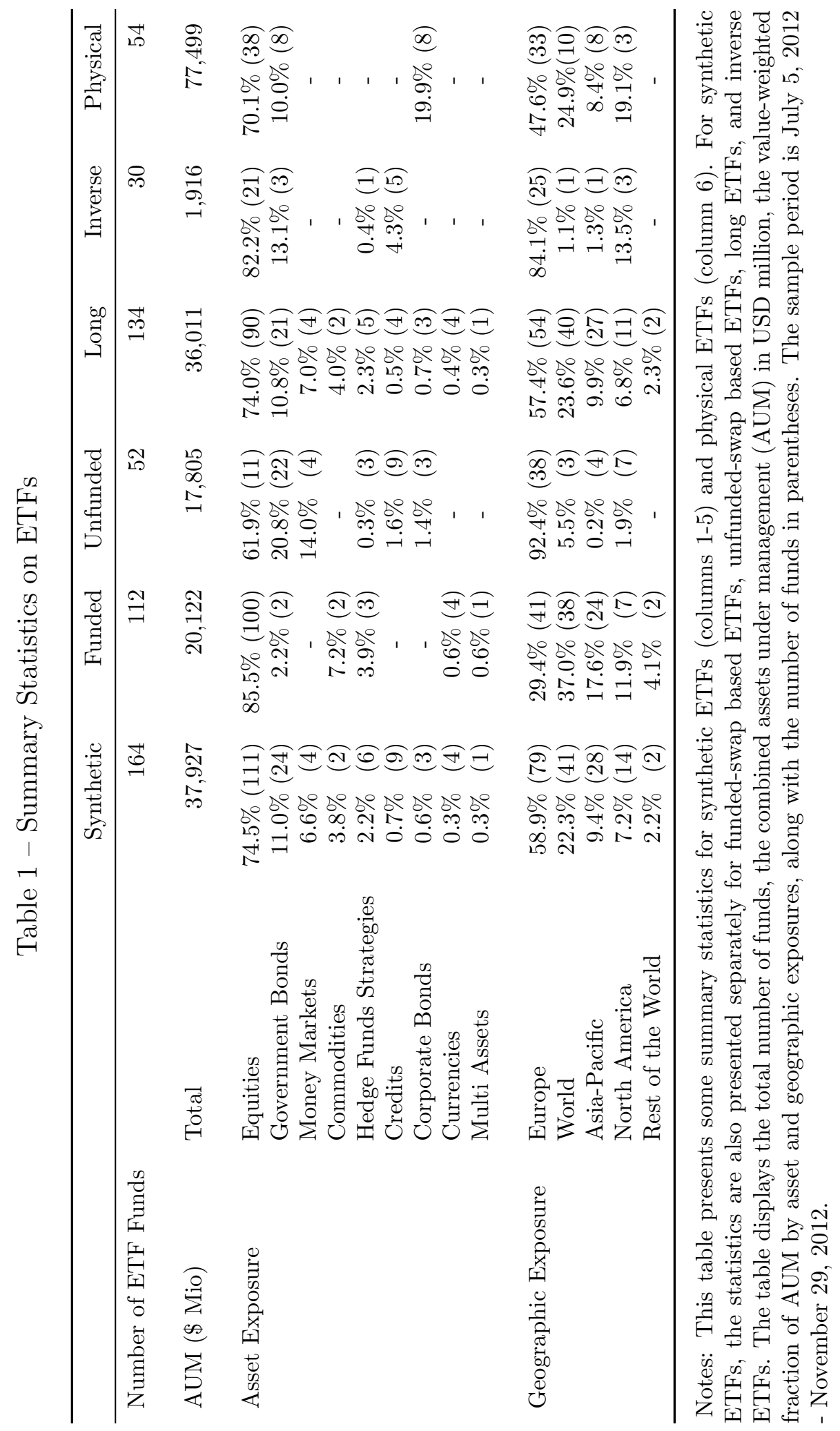




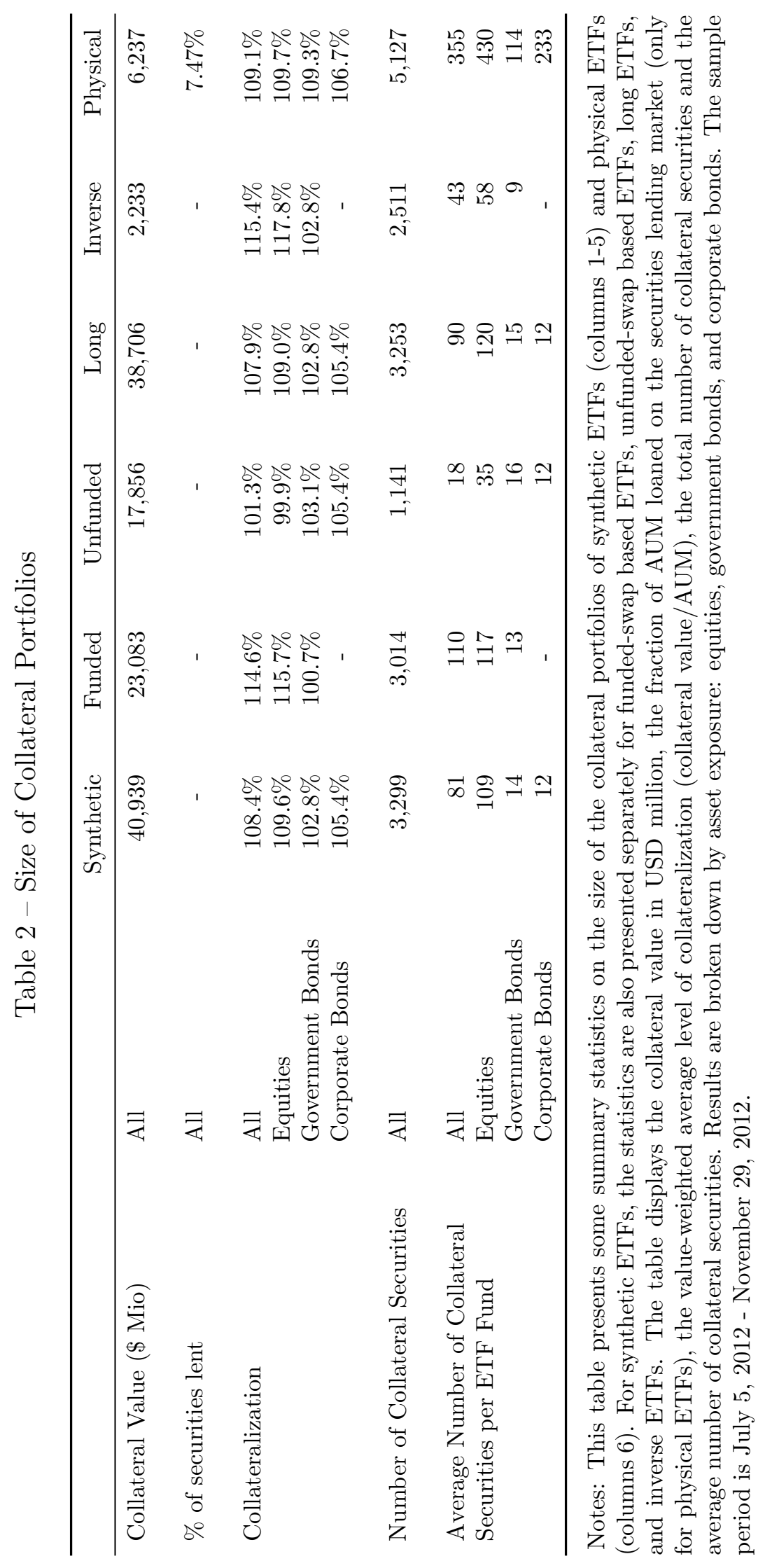


Table 3 - Types of Collateral Securities

\begin{tabular}{|c|c|c|c|c|c|c|}
\hline \multicolumn{7}{|c|}{ Panel A: Collateral Securities of Synthetic ETFs } \\
\hline \multicolumn{2}{|l|}{ Type of Collateral Securities } & Equity & \multicolumn{2}{|c|}{ Government Bonds } & \multicolumn{2}{|c|}{ Corporate Bonds } \\
\hline \multicolumn{2}{|c|}{ Number of Collateral Securities } & 2,591 & \multicolumn{3}{|c|}{490} & 218 \\
\hline \multirow{5}{*}{ ETF Asset Exposure } & All & $74.9 \%$ & & $5.4 \%$ \\
\hline & & $92.5 \%$ & \multicolumn{3}{|c|}{$2.7 \%$} & $4.8 \%$ \\
\hline & rnment Bonds & - & \multicolumn{3}{|c|}{$96.5 \%$} & $3.5 \%$ \\
\hline & orate Bonds & - & \multicolumn{3}{|c|}{$100 \%$} & - \\
\hline & & $40.8 \%$ & & $8.8 \%$ & & $10.4 \%$ \\
\hline \multicolumn{2}{|c|}{ Geographic Origin of the Collateral Securities } & Europe & Asia-Pacific & \multicolumn{2}{|c|}{ N. America } & R. World \\
\hline \multirow{6}{*}{ ETF Geographic Exposure } & All & $66.0 \%$ & $17.5 \%$ & & $16.3 \%$ & $0.2 \%$ \\
\hline & Europe & $71.8 \%$ & $13.9 \%$ & & $13.9 \%$ & $0.4 \%$ \\
\hline & Asia-Pacific & $56.0 \%$ & $24.1 \%$ & & $19.8 \%$ & $0.1 \%$ \\
\hline & North America & $58.3 \%$ & $22.1 \%$ & & $19.5 \%$ & $0.1 \%$ \\
\hline & Rest of the World & $58.1 \%$ & $25.5 \%$ & & $16.3 \%$ & $0.1 \%$ \\
\hline & World & $58.8 \%$ & $21.7 \%$ & & $19.4 \%$ & $0.1 \%$ \\
\hline \multicolumn{7}{|c|}{ Panel B: Collateral Securities of Physical ETFs } \\
\hline \multicolumn{2}{|l|}{ Type of Collateral Securities } & Equity & \multicolumn{2}{|c|}{ Government Bonds } & \multicolumn{2}{|c|}{ Corporate Bonds } \\
\hline \multicolumn{2}{|c|}{ Number of Collateral Securities } & 4,893 & \multicolumn{3}{|c|}{234} & - \\
\hline \multirow{4}{*}{$\begin{array}{ll}\text { ETF Asset Exposure } & \mathrm{Al} \\
& \mathrm{Ec} \\
& \mathrm{G} \\
& \mathrm{Cc}\end{array}$} & $\begin{array}{l}\text { All } \\
\text { Equity }\end{array}$ & $97.2 \%$ & \multicolumn{3}{|c|}{$2.8 \%$} & - \\
\hline & & $98.8 \%$ & \multicolumn{3}{|c|}{$1.2 \%$} & - \\
\hline & Government Bonds & $90.1 \%$ & \multicolumn{3}{|c|}{$9.9 \%$} & - \\
\hline & Corporate Bonds & $90.8 \%$ & \multicolumn{3}{|c|}{$9.2 \%$} & - \\
\hline \multicolumn{2}{|c|}{ Geographic Origin of the Collateral Securities } & Europe & Asia-Pacific & \multicolumn{2}{|c|}{ N. America } & R. World \\
\hline \multirow[t]{5}{*}{ ETF Geographic Exposure } & All & $18.2 \%$ & $50.8 \%$ & & $30.9 \%$ & $0.1 \%$ \\
\hline & Europe & $19.4 \%$ & $46.3 \%$ & & $34.2 \%$ & $0.1 \%$ \\
\hline & Asia-Pacific & $18.6 \%$ & $49.0 \%$ & & $32.3 \%$ & $0.1 \%$ \\
\hline & North America & $15.1 \%$ & $54.3 \%$ & & $30.5 \%$ & $0.1 \%$ \\
\hline & World & $18.8 \%$ & $53.8 \%$ & & $27.3 \%$ & $0.1 \%$ \\
\hline
\end{tabular}

Notes: This table presents some summary statistics on the securities used as collateral for synthetic ETFs (Panel A) and physical ETFs (Panel B). It displays the number of collateral securities per type of collateral and the value-weighted average percentage of collateral that is held in equity, governments bonds, and corporate bonds, respectively. It also presents for each type of ETF geographic exposure, the value-weighted percentage of collateral that comes from Europe, Asia-Pacific, North America, and Rest of the World, respectively. The government bond category also includes supranational bonds, government guaranteed bonds, government agency bonds, and German regional government bonds. The corporate bond category also includes covered bonds. The sample period is July 5, 2012 - November 29, 2012. 
Table 4 - Distribution of the Expected Collateral Shorftfall

\begin{tabular}{|c|c|c|c|c|c|c|c|c|c|}
\hline \multicolumn{10}{|c|}{ Panel A: Expected Collateral Shorftfall in $\%$ of the NAV } \\
\hline & {$[0-0.5[$} & {$[0.5-1[$} & & {$[1-5[$} & {$[5-10[$} & {$[10-15[$} & {$[15-20[$} & {$[20-25[$} & {$[25-35[$} \\
\hline Synthetic ETFs & $50.0 \%(45)$ & $2.0 \%(8)$ & & $3 \%(15)$ & $0.1 \%(1)$ & $0.7 \%(1)$ & - & $1.5 \%(2)$ & $1.4 \%(2)$ \\
\hline Physical ETFs & $99.1 \%(45)$ & $0.9 \%(1)$ & & - & - & - & - & - & - \\
\hline \multicolumn{10}{|c|}{ Panel B: Expected Collateral Shorftfall in $\$$ Million } \\
\hline & {$[0-1[$} & {$[1-5[$} & {$[5-10]$} & {$[10-20[$} & {$[20-40[$} & {$[40-60[$} & {$[60-80[$} & {$[80-100[$} & {$[100-140$} \\
\hline Synthetic ETFs & $70.3 \%$ & $14.8 \%$ & $2.7 \%$ & $2.7 \%$ & $2.7 \%$ & - & $4.0 \%$ & $1.4 \%$ & $1.4 \%$ \\
\hline Physical ETFs & $86.9 \%$ & $10.9 \%$ & $2.2 \%$ & - & - & - & - & - & - \\
\hline
\end{tabular}

Notes: This table reports, for all sample ETFs, the distribution of their expected collateral shortfall $S$. Panel A displays the value-weighted distribution of the expected collateral shortfall, along with the number of funds in parentheses. Panel B displays the distribution of the expected collateral shortfall in USD million. 
Table 5 - Fees and Tracking Errors

\begin{tabular}{|c|c|c|c|c|}
\hline \multicolumn{2}{|c|}{ Panel A: Summary Statistics } & \multirow{2}{*}{$\begin{array}{r}\text { All } \\
0.43(0.40)\end{array}$} & \multirow{2}{*}{$\begin{array}{r}\text { Physical } \\
0.44(0.40)\end{array}$} & \multirow{2}{*}{$\begin{array}{r}\text { Synthetic } \\
0.43(0.45)\end{array}$} \\
\hline Fees & All & & & \\
\hline & Capitalizing & $0.43(0.45)$ & $0.42(0.33)$ & $0.43(0.45)$ \\
\hline & Distributing & $0.44(0.40)$ & $0.44(0.40)$ & $0.44(0.50)$ \\
\hline \multirow[t]{3}{*}{ Tracking Errors } & & $0.36(0.04)$ & $0.96(0.72)$ & $0.13(0.03)$ \\
\hline & Capitalizing & $0.06(0.03)$ & $0.93(0.82)$ & $0.04(0.03)$ \\
\hline & Distributing & $0.84(0.67)$ & $0.96(0.71)$ & $0.60(0.48)$ \\
\hline \multicolumn{3}{|c|}{ Panel B: Regression Analysis } & Fees & Tracking Errors \\
\hline & \multicolumn{2}{|l|}{ Synthetic } & $\begin{array}{l}-0.090^{* * *} \\
(-4.25)\end{array}$ & $\begin{array}{l}-0.344^{* * *} \\
(-4.49)\end{array}$ \\
\hline & \multicolumn{2}{|l|}{ Distributing } & $\begin{array}{l}-0.025^{*} \\
(-1.75)\end{array}$ & $\begin{array}{l}0.279^{* * *} \\
(4.97)\end{array}$ \\
\hline & \multicolumn{2}{|l|}{$\log (\mathrm{AUM})$} & $\begin{array}{l}-0.003 \\
(-1.25)\end{array}$ & $\begin{array}{l}-0.030^{* * *} \\
(-3.48)\end{array}$ \\
\hline & \multicolumn{2}{|l|}{ Funded Swap } & $\begin{array}{r}0.026 \\
(1.27)\end{array}$ & $\begin{array}{l}-0.078 \\
(-1.54)\end{array}$ \\
\hline & \multicolumn{2}{|l|}{ Inverse } & $\begin{array}{l}0.085^{* * *} \\
(5.63)\end{array}$ & $\begin{array}{r}0.027 \\
(1.09)\end{array}$ \\
\hline $\begin{array}{l}\text { Asset } \\
\text { Exposure }\end{array}$ & \multicolumn{2}{|c|}{ Control Dummy Variables } & yes & yes \\
\hline \multirow{3}{*}{$\begin{array}{l}\text { Geographic } \\
\text { Exposure }\end{array}$} & \multicolumn{2}{|c|}{ Control Dummy Variables } & yes & yes \\
\hline & \multirow{2}{*}{\multicolumn{2}{|c|}{$\begin{array}{l}\text { Observations } \\
\mathrm{R}^{2}\end{array}$}} & 184 & 202 \\
\hline & & & 0.809 & 0.674 \\
\hline
\end{tabular}

Notes: Panel A displays the average (and median) fees and tracking errors in percentage points. We consider all sample ETFs, physical ETFs, and synthetic ETFs. We distinguish funds that pay out dividends to their investors (Distributing) from those that do not (Capitalizing). Fees correspond to total expense ratios and have been collected on November 29, 2014. Tracking errors are defined as the annualized standard-deviation of daily differences between the daily returns of the fund NAV and index. They are computed using two-year of daily returns covering the period November 29, 2010 - November 29, 2012. Panel B reports the OLS parameter estimates obtained by regressing the fees and tracking errors on a series of fund-specific variables. The estimation is based on the cross-section of all physical and synthetic ETFs. The explanatory variables are a dummy variable that takes a value of 1 if the ETF is synthetic, a dummy variable that takes a value of 1 if the fund pays out dividends to its investors (Distributing), the level of the ETF asset under management (in log), a dummy variable that takes a value of 1 if the ETF is based on a funded swap, a dummy variable that takes a value of 1 if the ETF is an inverse fund, as well as a dummy variable for each asset exposure and geographic exposure. We transform the explained variable, $\ln (\mathrm{y}+1)$, to ensure it remains non-negative. We display t-statistics in parentheses. ${ }^{* * *}$, $* *, *$ represent statistical significance at the $1 \%, 5 \%$ or $10 \%$ levels, respectively. 
Table 6 - Impact of Counterparty Risk on Fund Flows

\begin{tabular}{lcccc}
\hline & Outflows & Outflows & Outflows & Outflows \\
\hline Risk $\times$ Post & $0.227^{* *}$ & $0.189^{* *}$ & & \\
& $(2.51)$ & $(2.54)$ & & \\
Syn $\times$ Risk $\times$ Post & & & $0.140^{* * *}$ & $0.911^{* * *}$ \\
& & & $(2.84)$ & $(3.48)$ \\
Risk & -0.115 & -0.082 & -0.042 & -0.147 \\
& $(-1.48)$ & $(-1.29)$ & $(-1.13)$ & $(-0.75)$ \\
Post & $0.305^{* * *}$ & $0.224^{* * *}$ & $0.246^{* * *}$ & $1.077^{* * *}$ \\
& $(6.51)$ & $(5.87)$ & $(8.66)$ & $(7.19)$ \\
Perf & $-0.005^{* * *}$ & $-0.006^{* * *}$ & $-0.010^{* * *}$ & $-0.056^{* * *}$ \\
& $(-2.83)$ & $(-3.45)$ & $(-6.72)$ & $(-7.28)$ \\
Syn & & & $-0.101^{*}$ & $-2.217^{* * *}$ \\
& & & $(-1.95)$ & $(-5.56)$ \\
Sample & Equity Synthetic & All Synthetic & All Funds & All Funds \\
\hline Observations & & & 11,082 & 11,082 \\
\hline
\end{tabular}

Notes: This table reports the parameter estimates obtained by regressing an outflow variable on a dummy variable that takes a value of one if the 5-year CDS of the swap counterparty, Deutsche Bank, is greater than the 75th percentile of its distribution and zero otherwise (Risk), a dummy variable that takes a value of one after June 2011 and zero otherwise (Post), the return of the index tracked by the fund (Perf), and a dummy variable that takes a value of one if the fund is synthetic and zero otherwise (Syn). The estimation is based on all month-fund observations between August 2008 and December 2013. In columns 1-3, we estimate a Probit model where the explained variable takes a value of one if the monthly flow is negative and zero otherwise. In column 4, we estimate a Tobit model where the explained variable is the log of the absolute outflow. All models are estimated with fund random effects. We display t-statistics in parentheses. $* * *, * *, *$ represent statistical significance at the $1 \%, 5 \%$ or $10 \%$ levels, respectively. 
Table 7 - Actual vs. Optimal Collateral Portfolios

\begin{tabular}{|c|c|c|c|c|c|}
\hline \multicolumn{4}{|c|}{ Panel A: Collateral Securities and Expected Shortfall } & Actual Portfolios & \multirow{2}{*}{$\begin{array}{r}\text { Optimal Portfolios } \\
156\end{array}$} \\
\hline \multirow[t]{4}{*}{ Collateral Securities } & Total & & & 81 & \\
\hline & Equities & & & 47 & 129 \\
\hline & Government Bonds & & & 34 & 27 \\
\hline & Corporate Bonds & & & 0 & 0 \\
\hline \multirow{4}{*}{$\begin{array}{l}\text { Collateral Securities } \\
\text { per Fund }\end{array}$} & DAX ETF & & & 31 & 51 \\
\hline & Euro Stoxx 50 ETF & & & 28 & 71 \\
\hline & iBoxx Global Inflatio & -Linked & TTF & 30 & 40 \\
\hline & iBoxx Sovereigns Eur & zone $1-3$ & ETF & 9 & 36 \\
\hline \multirow{4}{*}{$\begin{array}{l}\text { Expected Collateral } \\
\text { Shortfall (S) }\end{array}$} & DAX ETF & & & $2.14 \%$ & $1.68 \%$ \\
\hline & Euro Stoxx 50 ETF & & & $2.04 \%$ & $1.42 \%$ \\
\hline & iBoxx Global Inflatio & -Linked & TTF & $0.95 \%$ & $0.79 \%$ \\
\hline & iBoxx Sovereigns Eur & zone 1-3 & ETF & $0.18 \%$ & $0.15 \%$ \\
\hline \multirow[t]{4}{*}{ Panel B: Eligible Co } & ateral Securities & Europe & Asia-Pacific & North America & a R. of the World \\
\hline & Equities & 373 & 882 & 172 & 1 \\
\hline & Government Bonds & 49 & 8 & 5 & - \\
\hline & Corporate Bonds & 23 & 1 & 3 & 3 \\
\hline
\end{tabular}

Notes: Panel A presents some descriptive statistics on the size, composition, and counterparty risk for the actual and optimal (see Section 5.2) collateral portfolios. Panel B displays all securities used as collateral in the 164 sample synthetic ETFs. All figures are as of November 29, 2012. 


\section{Appendix}

\section{Appendix A: Utility}

In this appendix, we show that maximizing the expected utility of the ETF investor corresponds to maximizing $\mathbb{E}[u(-\Delta(\omega))]$. As in Markowitz (1959), we assume that the consumption of the investor and its associated utility $u^{*}\left(r_{E T F}\right)$ depend on the return of the ETF, $r_{E T F}$. If the counterparty does not default, $r_{E T F}$ corresponds to $r_{i}$, the return of the NAV. If the counterparty defaults, the ETF issuer sells the collateral and transfers the proceeds to the investors. If the return of the collateral portfolio $r_{c}(\omega)$ is greater than or equal to $r_{i}$ (no collateral shortfall), the investors receive $r_{i}$ and the ETF issuer keeps the difference. On the contrary, if $r_{c}(\omega)<r_{i}$ (collateral shortfall), the investors only receive $r_{c}(\omega)$, a fraction of what they were supposed to receive according to the ETF contract. Formally, we have:

$$
r_{E T F}=\left\{\begin{array}{cl}
r_{i} & \text { if there is no default of the counterparty } \\
\min \left(r_{i}, r_{c}(\omega)\right) & \text { otherwise. }
\end{array}\right.
$$

Define $D$ as a binary variable that takes a value of 1 in case of default and 0 otherwise. The return $r_{E T F}$ can be expressed as:

$$
\begin{aligned}
r_{E T F} & =(1-D) \times r_{i}+D \times \min \left(r_{i}, r_{c}(\omega)\right) \\
& =(1-D) \times r_{i}+D \times\left(\min \left(0, r_{c}(\omega)-r_{i}\right)+r_{i}\right) \\
& =r_{i}+D \times \min (0,-\Delta(\omega))
\end{aligned}
$$

where $\Delta(\omega)=r_{i}-r_{c}(\omega)$ denotes the collateral shortfall (Equation (2)). Since $r_{i}$ and $D$ are not affected by the investor's choices, the investors' utility only depends on the collateral shortfall:

$$
u^{*}\left(r_{E T F}\right)=u^{*}\left(r_{i}+D \times \min (0,-\Delta(\omega))\right)
$$

As a result, $\omega^{*}=\underset{\omega \in \Theta_{t}}{\arg \max } \mathbb{E}\left[u^{*}\left(r_{E T F}\right)\right]$ is also the solution of the alternative program:

$$
\omega^{*}=\underset{\omega \in \Theta_{t}}{\arg \max } \mathbb{E}[u(-\Delta(\omega))]
$$

where $u($.$) is an indirect utility function defined for \Delta(\omega)>0$.

\section{Appendix B: Proof of Proposition 1}

Proof. If $\omega^{\top} \mu-\mu_{i}=\widetilde{\gamma}$ and $\lambda_{2}>0$, the Kuhn-Tucker conditions become:

$$
\begin{aligned}
\Sigma \omega-\Sigma_{i}-\lambda_{1} e-\lambda_{2} \mu & =0 \\
e^{\top} \omega-1 & =0 \\
\omega^{\top} \mu-\mu_{i}+\widetilde{\gamma} & =0
\end{aligned}
$$


From the first equation, we have:

$$
\omega=\Sigma^{-1} \Sigma_{i}+\lambda_{1} \Sigma^{-1} e+\lambda_{2} \Sigma^{-1} \mu
$$

Given this expression for $\omega$, the two constraints can be rewritten as:

$$
\begin{aligned}
1-e^{\top} \Sigma^{-1} \Sigma_{i} & =\lambda_{1} e^{\top} \Sigma^{-1} e+\lambda_{2} e^{\top} \Sigma^{-1} \mu \\
\mu_{i}-\widetilde{\gamma}-\mu^{\top} \Sigma^{-1} \Sigma_{i} & =\lambda_{1} e^{\top} \Sigma^{-1} \mu+\lambda_{2} \mu^{\top} \Sigma^{-1} \mu
\end{aligned}
$$

Define three three scalar terms $a, b$, and $c$ such that:

$$
a=e^{\top} \Sigma^{-1} e \quad b=e^{\top} \Sigma^{-1} \mu \quad c=\mu^{\top} \Sigma^{-1} \mu
$$

The constraints can be expressed as:

$$
\begin{aligned}
1-e^{\top} \Sigma^{-1} \Sigma_{i} & =\lambda_{1} a+\lambda_{2} b \\
\mu_{i}-\widetilde{\gamma}-\mu^{\top} \Sigma^{-1} \Sigma_{i} & =\lambda_{1} b+\lambda_{2} c
\end{aligned}
$$

Solving for $\lambda_{1}$ and $\lambda_{2}$, we have:

$$
\begin{aligned}
& \tilde{\lambda}_{1}=\frac{b\left(\mu_{i}-\widetilde{\gamma}-\mu^{\top} \Sigma^{-1} \Sigma_{i}\right)-c\left(1-e^{\top} \Sigma^{-1} \Sigma_{i}\right)}{b^{2}-a c} \\
& \tilde{\lambda}_{2}=\frac{b\left(1-e^{\top} \Sigma^{-1} \Sigma_{i}\right)-a\left(\mu_{i}-\widetilde{\gamma}-\mu^{\top} \Sigma^{-1} \Sigma_{i}\right)}{b^{2}-a c}
\end{aligned}
$$

By substituting $\widetilde{\lambda}_{1}$ and $\widetilde{\lambda}_{2}$ in the expression for $\omega$, we have:

$$
\begin{aligned}
\widetilde{\omega}= & \Sigma^{-1} \Sigma_{i}+\left(\frac{b\left(\mu_{i}-\widetilde{\gamma}-\mu^{\top} \Sigma^{-1} \Sigma_{i}\right)-c\left(1-e^{\top} \Sigma^{-1} \Sigma_{i}\right)}{b^{2}-a c}\right) \Sigma^{-1} e \\
& +\left(\frac{b\left(1-e^{\top} \Sigma^{-1} \Sigma_{i}\right)-a\left(\mu_{i}-\widetilde{\gamma}-\mu^{\top} \Sigma^{-1} \Sigma_{i}\right)}{b^{2}-a c}\right) \Sigma^{-1} \mu
\end{aligned}
$$

The standard mean-variance portfolio with a target mean $\mu_{i}-\widetilde{\gamma}$ is the solution of the following program:

$$
\begin{aligned}
& \min _{\omega} \frac{1}{2} \omega^{\top} \Sigma \omega \\
& \text { subject to } \quad\left\{\begin{array}{l}
\omega^{\top} \mu=\mu_{i}-\widetilde{\gamma} \\
e^{\top} \omega=1 \in \mathbb{N}^{K}
\end{array}\right.
\end{aligned}
$$

The corresponding optimal solution is:

$$
\widetilde{\omega}_{M V}=\left(\frac{b \mu_{i}-b \widetilde{\gamma}-c}{b^{2}-a c}\right) \Sigma^{-1} e+\left(\frac{b-a \mu_{i}+a \widetilde{\gamma}}{b^{2}-a c}\right) \Sigma^{-1} \mu
$$

As a consequence, we have:

$$
\begin{gathered}
\widetilde{\omega}=\widetilde{\omega}_{M V}+\Sigma^{-1} \Sigma_{i}+\left(\frac{c e^{\top}-b \mu^{\top}}{b^{2}-a c}\right) \Sigma^{-1} \Sigma_{i} \Sigma^{-1} e \\
+\left(\frac{a \mu^{\top}-b e^{\top}}{b^{2}-a c}\right) \Sigma^{-1} \Sigma_{i} \Sigma^{-1} \mu
\end{gathered}
$$


Table A1 - Equities Used as Collateral

\begin{tabular}{|c|c|c|c|c|c|c|c|c|}
\hline \multicolumn{9}{|c|}{ Panel A: Equity Issuer } \\
\hline \multicolumn{2}{|c|}{ Region } & \multicolumn{2}{|c|}{$\begin{array}{r}\text { Europe } \\
58.5 \%(752)\end{array}$} & \multicolumn{2}{|c|}{$\begin{array}{r}\text { Asia-Pacific } \\
21.6 \%(1,365)\end{array}$} & $\begin{array}{l}\text { N. America } \\
19.6 \%(469)\end{array}$ & \multicolumn{2}{|c|}{$\begin{array}{l}\text { R. World } \\
0.3 \%(5)\end{array}$} \\
\hline \multicolumn{2}{|c|}{ Industry Classification } & \multicolumn{2}{|c|}{$\begin{array}{r}\text { Industrial } \\
76.6 \%(2,047)\end{array}$} & \multicolumn{2}{|c|}{$\begin{array}{r}\text { Financial } \\
11.4 \%(346)\end{array}$} & $\begin{array}{r}\text { Utility } \\
10.4 \%(127)\end{array}$ & \multicolumn{2}{|c|}{$\begin{array}{r}\text { Transportation } \\
1.6 \%(71)\end{array}$} \\
\hline \multicolumn{2}{|c|}{ Market Capitalization } & \multicolumn{2}{|c|}{$\begin{array}{r}\text { Micro-Cap } \\
1.4 \%(30)\end{array}$} & \multicolumn{2}{|c|}{$\begin{array}{r}\text { Small-Cap } \\
9.3 \%(1,634)\end{array}$} & $\begin{array}{l}\text { Mid-Cap } \\
9.9 \%(404)\end{array}$ & \multicolumn{2}{|c|}{$\begin{array}{l}\text { Large-Cap } \\
79.4 \%(523)\end{array}$} \\
\hline \multicolumn{4}{|l|}{ Panel B: Liquidity } & mean & median & st.dev. & $\min$ & $\max$ \\
\hline \multicolumn{4}{|c|}{ Average Daily Spread } & $0.21 \%$ & $0.20 \%$ & $0.48 \%$ & $0.01 \%$ & $12.73 \%$ \\
\hline \multicolumn{4}{|c|}{ Average Daily Volume } & $4.67 \%$ & $0.44 \%$ & $21.83 \%$ & $0.01 \%$ & $115.15 \%$ \\
\hline \multicolumn{4}{|c|}{ Panel C: Dependence } & mean & median & st.dev. & $\min$ & $\max$ \\
\hline \multirow{2}{*}{ Beta } & ETF & & & 0.48 & 0.45 & 0.70 & -1.83 & 3.04 \\
\hline & Swap Coun & party & & 0.30 & 0.28 & 0.28 & -0.06 & 1.11 \\
\hline \multirow[t]{3}{*}{ Conditional Beta } & $\mathrm{ETF}$ & & & 0.50 & 0.47 & 0.74 & -3.05 & 4.14 \\
\hline & Swap Coun & party & & 0.35 & 0.33 & 0.30 & -0.46 & 1.06 \\
\hline & & & $<0$ & {$[0 ; 0.2[$} & {$[0.2 ; 0.4[$} & {$[0.4 ; 0.6[$} & {$[0.6 ; 0.8[$} & $\geq 0.8$ \\
\hline \multirow[t]{2}{*}{ Beta } & $\mathrm{ETF}$ & & $7.5 \%$ & $11.3 \%$ & $25.3 \%$ & $21.4 \%$ & $13.4 \%$ & $21.1 \%$ \\
\hline & Swap Coun & party & $0.4 \%$ & $36.6 \%$ & $38.3 \%$ & $19.3 \%$ & $4.2 \%$ & $1.2 \%$ \\
\hline \multirow[t]{2}{*}{ Conditional Beta } & $\mathrm{ETF}$ & & $9.2 \%$ & $9.1 \%$ & $22.9 \%$ & $20.9 \%$ & $14.4 \%$ & $23.5 \%$ \\
\hline & Swap Coun & party & $0.2 \%$ & $23.9 \%$ & $40.2 \%$ & $25.3 \%$ & $8.8 \%$ & $1.6 \%$ \\
\hline
\end{tabular}

Notes: This table presents some summary statistics on the equities included in the collateral portfolios of synthetic ETFs. Panel A displays the value-weighted percentage of collateral equities by region, industry, and size of the issuer, along with the number of different equities in parentheses. We use the following definitions for size groups: Micro-Cap: below $\$ 100$ million; Small-Cap: $\$ 100$ million- $\$ 4$ billion; Mid-Cap: $\$ 4$ billion- $\$ 10$ billion; Large-Cap: Over $\$ 10$ billion. These ranges were selected to match the average market capitalization of the MSCI World Index of the respective categories. The size figures are as of November 29th, 2012. Panel B displays value-weighted statistics about the average daily percentage bid-ask spread and the average daily volume in percentage of the market capitalization. For each security, the percentage spread and volume are winsorized at the top $1 \%$. Panel $\mathrm{C}$ displays value-weighted statistics on the beta coefficient $\left(\beta_{i, j}\right)$ and conditional beta coefficient $\left(\beta_{i, j} \mid r_{j}<0\right)$ of the collateral equities with respect to the ETF return and to the swap counterparty return (Deutsche Bank stock return). We compute the conditional betas by using only days during which the index return or the swap counterparty return is negative. The lower part of Panel $\mathrm{C}$ presents summary statistics on the distribution of the betas and conditional betas, weighted by the equity value. In Panels B and C, the sample period is between January 1, 2007 and December $31,2012$. 
Table A2 - Bonds Used as Collateral

\begin{tabular}{|c|c|c|c|c|c|c|c|c|c|c|}
\hline \multicolumn{2}{|c|}{ Panel A: Bond Issuer } & \multicolumn{2}{|c|}{ Europe } & \multicolumn{3}{|c|}{ N. America } & \multicolumn{2}{|c|}{ Asia-Pacific } & \multicolumn{2}{|c|}{ R. World } \\
\hline Bond Type & $\begin{array}{l}\text { All } \\
\text { Gov. Bonds } \\
\text { Corp. Bonds }\end{array}$ & \multicolumn{2}{|c|}{$\begin{array}{l}88.3 \%(512) \\
86.0 \%(338) \\
96.6 \%(174)\end{array}$} & \multicolumn{3}{|c|}{$\begin{array}{l}7.1 \%(118) \\
8.6 \%(101) \\
2.0 \%(17)\end{array}$} & \multicolumn{2}{|c|}{$\begin{array}{l}4.5 \%(77) \\
5.4 \%(51) \\
1.3 \%(26)\end{array}$} & \multicolumn{2}{|c|}{$\begin{array}{c}0.1 \%(1) \\
- \\
0.1 \%(1)\end{array}$} \\
\hline \multicolumn{2}{|l|}{ Panel B: Rating } & AAA & & \multicolumn{3}{|c|}{$\mathrm{AA}$} & $\mathrm{BBB}$ & $\mathrm{BB}$ & B & $\mathrm{n} / \mathrm{a}$ \\
\hline Bond Type & $\begin{array}{l}\text { All } \\
\text { Gov. Bonds } \\
\text { Corp. Bonds }\end{array}$ & $\begin{array}{l}65.5 \% \\
75.2 \% \\
30.4 \%\end{array}$ & \multicolumn{2}{|c|}{$\begin{array}{r}14.8 \% \\
9.3 \% \\
34.5 \%\end{array}$} & \multicolumn{2}{|c|}{$\begin{array}{l}17.2 \% \\
15.3 \% \\
23.9 \%\end{array}$} & $\begin{array}{l}0.8 \% \\
0.1 \% \\
3.5 \%\end{array}$ & $\begin{array}{l}0.3 \% \\
0.1 \% \\
1.5 \%\end{array}$ & $\begin{array}{c}0.1 \% \\
- \\
0.1 \%\end{array}$ & $\begin{array}{c}1.3 \% \\
- \\
6.1 \%\end{array}$ \\
\hline Bond Issuer & $\begin{array}{l}\text { Europe } \\
\text { North America } \\
\text { Asia-Pacific }\end{array}$ & $\begin{array}{l}66.0 \% \\
93.9 \% \\
19.8 \%\end{array}$ & \multicolumn{2}{|c|}{$\begin{array}{r}12.6 \% \\
0.4 \% \\
69.9 \%\end{array}$} & $\begin{array}{r}19.2 \\
0.1 \\
3.5\end{array}$ & $\begin{array}{l}2 \% \\
1 \% \\
5 \%\end{array}$ & $\begin{array}{l}0.9 \% \\
0.1 \% \\
0.4 \%\end{array}$ & $\begin{array}{l}0.2 \% \\
1.8 \% \\
1.1 \%\end{array}$ & $\begin{array}{cc}0 & 0.1 \% \\
0 & 0.2 \% \\
0 & -\end{array}$ & $\begin{array}{l}1.0 \% \\
3.5 \% \\
5.3 \%\end{array}$ \\
\hline \multicolumn{2}{|c|}{ Panel C: Maturity } & \multicolumn{2}{|c|}{$<1 \mathrm{Y}$} & \multicolumn{2}{|c|}{$1-3 Y$} & $3-5 \mathrm{Y}$ & \multicolumn{2}{|c|}{$5-7 \mathrm{Y}$} & $7-10 \mathrm{Y}$ & $>10 \mathrm{Y}$ \\
\hline Bond Type & $\begin{array}{l}\text { All } \\
\text { Gov. Bonds } \\
\text { Corp. Bonds }\end{array}$ & \multicolumn{2}{|c|}{$\begin{array}{l}16.4 \% \\
11.7 \% \\
33.4 \%\end{array}$} & $\begin{array}{l}19.2 \% \\
43.0 \%\end{array}$ & & $\begin{array}{l}13.3 \% \\
19.6 \%\end{array}$ & & $\begin{array}{l}8.5 \% \\
0.5 \%\end{array}$ & $\begin{array}{r}14.7 \% \\
18.1 \% \\
2.3 \%\end{array}$ & $\begin{array}{r}23.1 \% \\
29.2 \% \\
1.2 \%\end{array}$ \\
\hline Bond Issuer & $\begin{array}{l}\text { Europe } \\
\text { North America } \\
\text { Asia-Pacific }\end{array}$ & \multicolumn{2}{|c|}{$\begin{array}{r}17.4 \% \\
4.5 \% \\
17.9 \%\end{array}$} & $\begin{array}{l}25.3 \% \\
21.7 \% \\
14.4 \%\end{array}$ & & $\begin{array}{l}14.7^{\circ} \\
18.8^{\circ} \\
12.49\end{array}$ & $\begin{array}{l}\% \\
\% \\
\%\end{array}$ & $\begin{array}{l}.4 \% \\
.0 \% \\
.4 \%\end{array}$ & $\begin{array}{l}13.2 \% \\
16.7 \% \\
28.1 \%\end{array}$ & $\begin{array}{r}23.0 \% \\
30.3 \% \\
9.8 \%\end{array}$ \\
\hline Index Maturity & $\begin{array}{ll}\text { y } & \text { Short } \\
& \text { Medium } \\
\text { Long }\end{array}$ & $\begin{array}{l}21 . \\
10 . \\
-\end{array}$ & & $\begin{array}{r}49.5 \% \\
8.9 \% \\
-\end{array}$ & & $\begin{array}{c}23.7^{\circ} \\
22.7^{9} \\
-\end{array}$ & & $\begin{array}{l}.3 \% \\
.0 \% \\
.5 \%\end{array}$ & $\begin{array}{r}1.0 \% \\
23.7 \% \\
7.6 \%\end{array}$ & $\begin{array}{c}0.9 \% \\
- \\
84.9 \%\end{array}$ \\
\hline
\end{tabular}

Notes: This table presents some summary statistics on the bonds included in the collateral portfolios of synthetic ETFs. Panel A displays the value-weighted percentages of collateral bonds by region, along with the number of different bonds in parentheses. Panel B presents the value-weighted percentages of collateral bonds by bond rating, for different bond types and issuers. The $\mathrm{n} / \mathrm{a}$ category corresponds to unrated bonds. Panel $\mathrm{C}$ displays the valueweighted percentages of collateral bonds by bucket of maturity, for different bond types and issuers. Short, Medium, and Long refer to funds that track a bond index with, respectively, a short maturity (less than 3 years), a medium maturity (between 3 and 10 years), and a long maturity (more than 10 years). The sample period is July 5, 2012 - November 29, 2012. 